NBER WORKING PAPER SERIES

\title{
WOULD YOU BUY A HONDA MADE IN THE U.S.? THE IMPACT OF PRODUCTION LOCATION ON MANUFACTURING QUALITY
}

\author{
Nicola Lacetera \\ Justin R. Sydnor \\ Working Paper 18005 \\ http://www.nber.org/papers/w18005 \\ NATIONAL BUREAU OF ECONOMIC RESEARCH \\ 1050 Massachusetts Avenue \\ Cambridge, MA 02138 \\ April 2012
}

We are grateful to seminar participants at the Massachusetts Institute of Technology, the National Bureau of Economic Research, the University of Wisconsin Madison, the University of Michigan, the University of Toronto, the Georgia Institute of Technology, Case Western Reserve University, London Business School, and Cleveland State University for their comments. Special thanks to Susan Helper, Glenn Mercer, and Jim Rebitzer for help obtaining data and advice on the auto industry, and to Heather Royer for sharing her econometric expertise. Christian Catalini, Tianli Chen, Jonathan Evans, James Graulty, Brian Jameson, Vivek Kartha, and Yugarshi Mondal provided excellent research assistance. Financial support from the International Motor Vehicle Program is gratefully acknowledged. The views expressed herein are those of the authors and do not necessarily reflect the views of the National Bureau of Economic Research.

NBER working papers are circulated for discussion and comment purposes. They have not been peerreviewed or been subject to the review by the NBER Board of Directors that accompanies official NBER publications.

(C) 2012 by Nicola Lacetera and Justin R. Sydnor. All rights reserved. Short sections of text, not to exceed two paragraphs, may be quoted without explicit permission provided that full credit, including (C) notice, is given to the source. 
Would You Buy a Honda Made in the U.S.? The Impact of Production Location on Manufacturing Quality

Nicola Lacetera and Justin R. Sydnor

NBER Working Paper No. 18005

April 2012, Revised June 2012

JEL No. D24,F23,L62,M11

\begin{abstract}
Are location-specific factors - such as the education and attitude of the local workforce, supplier networks, institutional infrastructure, and local "culture"-important for understanding persistent heterogeneities among firms? We address this question in the context of the automobile industry. Using a unique data set of over 565,000 used-car transactions at wholesale auctions, we test whether the long-run value and quality of otherwise identical cars depends on the country of assembly. We exploit the natural experiment provided by the establishment of assembly plants in the U.S. by Japanese auto manufacturers, and the fact that some of the most popular Japanese car models are assembled both in Japan and the U.S. We find evidence that the Japan-assembled cars on average sell for more than those built in the U.S., but the estimated difference is only $\$ 62$. The average differences are driven almost entirely by older-model Toyotas, for which we find a more meaningful difference between the Japanese and U.S. built cars. For Hondas and more recent models of Toyotas, the Japan-built cars are no more valuable than those built in the U.S. These results suggest that Japanese automakers have been successful, though perhaps with some lag, at transferring their high-quality practices to their U.S. transplants. Our findings also suggest that there is not an inherent limitation to the U.S. manufacturing environment that prevents the production of high-quality cars in America.
\end{abstract}

Nicola Lacetera

University of Toronto

105 St. George Street

Toronto, ON M5S 2E9

Canada

and NBER

nicola.lacetera@utoronto.ca

Justin R. Sydnor

University of Wisconsin - Madison

975 University Avenue

Madison, WI 53706

jsydnor@bus.wisc.edu 


\section{Introduction}

There is a large literature documenting that seemingly similar companies often differ systematically in important measures of performance, including productivity and profitability. Syverson (2011) provides a detailed review of studies documenting productivity differences, and Van Reenen (2010) has identified understanding the sources of firm heterogeneity as one of the current "grand challenges" in the social sciences. ${ }^{1}$ Although this literature has long focused on assessing the relative influence of firm-specific vs. industry-specific factors, ${ }^{2}$ a few studies have suggested that some of the sources of a firm's advantage or disadvantage might be location-specific. Bloom, Sadun and Van Reenen (2012) distinguish between a "natural" (or location-specific) advantage hypothesis versus a "management" hypothesis to explain the sources of differential performance, and other studies suggest that there may be important country-level influences on firm outcomes. ${ }^{3}$ These factors include the education and attitude of the local workforce, supplier networks, and, more broadly, the institutional infrastructure and "culture." Grossman and Maggi (2000), for example, posit that the diversity of talent within countries may explain the advantage of different economies in products whose success depend on the outstanding performance of a few individuals (e.g., software production in the U.S.) and for those relying on many complementary parts and quality control (e.g., automobile production in Japan).

Understanding the role that location plays in firm performance is particularly relevant because of the increasing role of multinational companies. There is great interest in investigating multinationals' ability to transfer their practices to different locations. Some studies have shown convergence in organizational practices and productivity across plants in different countries whereas others find that firms have difficulty replicating the practices of the home country's plants abroad. ${ }^{4}$ It is often challenging, however, to empirically identify the effect of location-specific factors on firm outcomes because it is difficult to separate their role from other aspects of the firm. Moreover, even if firm and industry-specific factors are controlled for, companies might be producing different products (and for different markets) in different places, thus making the comparison of outcomes across locations hard to interpret.

In this paper, we examine the question of location-specific production effects in the context of the automobile market. We exploit a natural experiment provided by the presence of assembly plants of

1 Other studies theorizing and documenting heterogeneity between and within industries include Aghion and Howitt, 2009; Argote and Epple, 1990; Gibbons and Henderson, 2012; Hayes and Clark, 1985; Helpman, Melitz and Yeaple, 2004; Ichniowski, Shaw, and Prennushi, 1997; Jovanovic, 1982; Leibenstein, 1987; Lippman and Rumelt, 1982; Nelson and Winter, 1982; Redding, 2011; and Syverson, 2004.

2 McGahan and Porter 1997, 1999; Rumelt, 1991; Schmalensee, 1985.

3 See for example: Bartelsman, Haskel and Martin, 2008; Barrell and Pain, 1999; Council of Competitiveness and Deloitte, 2010; Khanna and Rivkin, 2001; Makino, Isobe and Chan, 2004; Pisano and Shih, 2009; Porter, 1998.

${ }^{4}$ See among others: Abo, 1994; Beechler and Yang 1994; Doeringer, Lorenz and Terkla, 2003; Freeman and Shaw, 2009; Gertler, 2001; Liker, Fruin and Adler, 1999; Lowe, Morris and Wilkinson, 2000; McGahan and Victer, 2010. 
Japanese auto-manufacturers in the U.S. In addition to producing in their home-country plants, Japanese car manufacturers established production plants in the U.S. in response to exchange-rate fluctuations and the Voluntary Export Restraints of the early 1980s (Russ, 2009). Honda and Nissan set up their first American assembly plants in 1982, and their move was soon followed by all other major Japanese car makers (Chung, Mitchell and Yeung, 2003; Russ, 2009). These plants have, increasingly, employed the local workforce (both on the shop floor and in managerial positions) and relied on U.S.-based parts suppliers (Abo, 1994; Chung et al., 2003; Dertouzos, Lester and Solow, 1989; Hashimoto, 1994; Klier and Rubenstein, 2008). Because a number of Japanese car models, including some very popular, highvolume automobiles, are produced in both Japan-based and U.S.-based plants (e.g., Honda Accord, Toyota Camry), it is possible to assess whether the short- and long-run quality of cars is affected by the country of production, holding industry and company-level factors fixed, as well as observable features of the products.

We use a unique dataset from a leading provider of wholesale used car auctions in the U.S., which includes over 565,000 Japanese-make used cars brought to auction between 2002 and 2008. We focus on Japanese car models produced both in the U.S. and Japan, and sold in the American market. The data contain detailed information on each car. Because of the richness of the data, we can identify essentially identical cars at the auction: for instance, the sample of 2002 Honda Accord SE 4-door sedans with 4cylinder engines sold in 2005 at the auction site in Chicago. Importantly, we also observe the Vehicle Identification Number (VIN) that lists the country of manufacture for each vehicle. With that information, we investigate whether there are long-run quality differences for otherwise identical Japanese-make cars depending on whether they were assembled in the U.S. or Japan. The idea behind this empirical strategy is similar to that adopted by Bloom et al. (2012), who analyze differences in the impact of IT adoption on productivity between U.S.-owned and non-U.S.-owned "observationally identical" plants in the U.K. This strategy allowed them to separate location-specific factors from management-level determinants of the effectiveness of IT investments. Our approach is also similar to that adopted by Mas (2008), who uses data from construction equipment resale markets to study differences in production quality across plants.

Our primary measure of quality is simply the sale price. The bidders at wholesale auctions are usedcar dealers who intend to resell cars to final customers. Given the competitive nature of these auctions, any observable quality differences should be incorporated into the sale price of used cars. Thus, for our main analysis, we run regressions of sale price on an indicator of whether the car was produced in Japan or the U.S., controlling for key observable characteristics of the car (e.g., mileage, auction location). For the average car model in our sample, we find a statistically significant yet very modest difference in sale prices, with cars assembled in Japan selling for an estimated \$62 more than their U.S.-produced 
counterparts. Compared to the average sale price of $\$ 8,545$, this estimate implies that Japanese-built cars sell for around 1\% more. At the 95\% confidence level, we can rule out that the average difference is any more than $\$ 77$.

In addition to sale prices, we examine other more direct measures of quality, including an estimate of the costs to recondition the car provided by the auction company, whether it was auctioned with announced defects, whether it sold at the auction, and, conditional on selling, whether there was a problem with the car that resulted in after-sale arbitration between the buyer and seller. All else equal, we find no significant differences between Japanese-built and U.S.-built Japanese cars along any of these quality dimensions. The only statistically significant difference is that Japanese-built cars are approximately 1 percentage point more likely to sell at auction, again a modest increase off of a base rate of $64 \%$. These modest differences suggest that the Japanese automakers were largely able to transfer their practices to their plants in the U.S. in such a way that the cars assembled in the two countries do not show significant long-run quality differences.

The average estimates do, however, hide some interesting heterogeneity. Our dataset is dominated by two car models: the Honda Accord and the Toyota Camry, which are consistently two of the top-selling vehicles in the U.S. market. Looking separately at the two automakers reveals rather different patterns. On average, we find no difference in the sale prices of Hondas produced in Japan versus the U.S. For Honda Accords produced from 1999 through 2004, we see essentially no difference in resale values across Japanese and U.S.-produced models, even for cars as old as 8 years. For Accords produced in the early 1990s, which are generally over 10 years old by the time they reach auctions in our dataset, some (imprecisely estimated) differences begin to emerge, with Japanese cars selling for roughly $4 \%$ more. For Toyota, the average price difference is approximately $\$ 100$ in favor of Japanese-built cars. Toyota Camrys produced between 1993 and 2001 show average differences between Japanese and American assembled cars of approximately 3\%, which can be as much as a few hundred dollars for 2- to 3-year old cars. There is also an important break in the pattern for Toyota that coincides with a substantial redesign of the Toyota Camry that took place starting with the 2002 model year. After the 2002 redesign, the Japanese-built advantage disappeared and actually seems to have reversed, with the American-built Camrys showing 1-2\% higher resale values.

Our paper provides new insights into the transferability of practices and performance within organizations, an issue of particular relevance for multinational companies as they try to transfer their practices to their foreign "transplants." Taken together, our results suggest that Honda and Toyota were largely able to transfer their quality-production techniques to their U.S. plants. For Honda in particular, which began production in the U.S. approximately 5 years before Toyota, that transfer appears to have been completely successful by the late 1990s. These results add a new dimension to a small literature that 
has attempted to assess, with mixed results, whether the Japanese transplants differ from the auto assembly plants in Japan in terms of productivity and the adoption of certain management practices. ${ }^{5}$ More broadly, our findings are consistent with others that have documented the ability of multinationals to transfer their practices in multiple countries, such as Bloom et al. (2012), who show that U.S. multinationals have been able to obtain similar levels of productivity increase from investments in IT in their U.S.- and U.K.-based establishments. However, with the case of Toyota, we also see evidence that this transfer is not always complete and does not always occur quickly, which is consistent with Pil and MacDuffie (1999), who document that multinationals may at times need to work to adapt their practices to the host country. The case of Toyota, moreover, does not look consistent with gradual adaptation and convergence; rather, the transfer appears to have occurred suddenly after a major model redesign.

The data and empirical approach in this study represent a substantial contribution to the literature on cross-plant performance differences. Much of the existing literature is based on small sample sizes and case studies. Furthermore, in many existing studies, the plants being analyzed may produce different products (or versions of a product), making comparisons harder to interpret. By contrast, our work is based on a dataset with half a million observations and allows us to compare products at a very granular level. Additionally, whereas most related studies focus on productivity as the outcome of interest, we examine whether there are differences in longer-run product quality. The data also allow us to explore whether quality differences emerge at various points in the products' life cycle. These are important questions for the automobile sector and, more generally, for high-priced durable goods industries.

Our findings here may also speak to the broader debates about the state of auto manufacturing in the U.S. In the wake of the recent crisis and government intervention in the U.S. automotive industry, there has been renewed interest in understanding the origins of performance differentials between American and Japanese car manufacturers. Japanese cars are generally perceived to be of higher quality and more reliable, and many scholars have argued that this quality premium is the key to the success of Japanese brands in the North American market. ${ }^{6}$ Figure 1, which is based on a large sample of popular Japanese-make and U.S.-make cars sold at the wholesale auctions, confirms that these perceived quality differences are reflected in resale prices of cars from the two countries. The resale values of Japanese cars produced in the 1990s and early 2000s fell much slower as cars aged than did those of cars produced by U.S. manufacturers during this period. But what is the source of this Japanese advantage? Better design, management practices, and corporate culture in Japanese firms have long been identified as the

5 These studies include Fucini and Fucini, 1990; Graham, 1995: Hashimoto, 1994: Kenney and Florida, 1995: Pil and MacDuffie, 1999: and Shibata, 2001.

6 See for example: Barber and Darrough, 1996; Cusumano, 1988; Fujimoto, 2000; Helper, 1991; JD Power and Associates, 2010; Shimokawa, 2010; Train and Winston, 2007; and Womak, Jones, and Roos, 1990. 
main determinants of this quality differential (Womack et al., 1990; Yates, 1983). However, a number of studies have also highlighted location-specific characteristics of the American environment itself (e.g., labor relations, supplier networks, and workers' attitudes and education) that might affect the ability to produce high-quality cars (Dassbach, 1994; Dore and Sako, 1998; Hashimoto, 1994; Helper, 1991; Hofstede, 1984; Ingrassia and White, 1994; Sako and Helper, 1998). There are limits to what our analysis can reveal about the sources of Japanese quality advantages. For example, the Japanese assembly plants are not unionized, and, for this reason, our analysis cannot inform debates about whether unionization affects the ability of the American manufacturers to improve their production quality. Nonetheless, our findings that Honda and Toyota were able (though with a substantial lag for Toyota) to achieve similar levels of long-run quality for cars assembled in the U.S. suggest that it is possible for foreign manufacturers to produce high-quality cars in the U.S. Accordingly, the key sources of the Japanese quality advantage are unlikely to be strongly related to inherently location-specific features of the U.S. manufacturing environment.

The paper proceeds as follows. In the next section, we offer background information on the wholesale used car auction company from which the data were obtained, and describe the data in this study. In Section 3 we present our empirical findings. We first report graphical analyses and then introduce our regression results, including a range of robustness checks, and investigate the heterogeneity in our data. In Section 4, we conclude with a discussion of some potential implications of our findings for understanding how firms transfer their practices to foreign locations.

\section{Institutional Context and Data}

The data for this study come from one of the largest operators of wholesale used-car auctions in the United States. ${ }^{7}$ We first offer some details of the auction process, and then describe the data.

The wholesale auction process starts when a seller brings a used car to one of the company's 89 auction facilities located throughout the U.S. Details of the car are registered into the company's system. The seller can then purchase detailing or reconditioning services from the auction company before a car is auctioned. Examples of reconditioning would include body work or repainting. Auction sites typically hold auctions once or twice a week. On these auction days, licensed used-car dealers come to the auction to purchase cars for resale. Depending on the particular auction site, more than 2,000 transactions can occur in a day. Most auction sites have somewhere between 4 and 7 auction lanes operating

\footnotetext{
7 The wholesale used automobile market is comparable in size to the market for new vehicles. The National Auto Auction Association reports that in 2009, for example, 8.9 million used vehicles were sold at wholesale auction in the U.S., compared to 10.4 million new cars.
} 
simultaneously, through which cars are driven and put onto the auction block. Once on the auction block, the used-car dealers bid for them in a standard English (oral ascending-price) auction that lasts around 2 minutes per car. The highest bidder receives the car and can take it back to his used-car lot himself (by driving it or placing it on a truck), or can arrange delivery through independent delivery agencies that operate at the auctions. After the auction ends, if the buyers discover a significant defect with the car that was not disclosed by the seller at the auction, the auction company provides an arbitration procedure that allows buyers to demand compensation from the seller and, potentially, to return the car for a refund.

Although the auctions occur quickly, the buyers at the auctions can observe a lot about the car that might influence the price they are willing to pay. Upon arriving at the auction site, buyers can print off a list of the cars for sale that day that includes basic information about each car. The cars are available on the lots prior to being auctioned for inspection by the dealers. As the time approaches for the auction, the car is driven slowly to the auction block in a line with other vehicles. Dealers can walk along with the cars and inspect them as they roll through that line. Finally, when a car is on the auction block, there is a screen that shows information about the car, including disclosures that the sellers make about defects or features of the car.

Our data contain information about the auction outcome and other details for each car brought to auction from January 2002 through September 2008. The full dataset contains information on just over 27 million cars. We observe information about each car, including its make, model, body style, model year, and odometer mileage as well as an identifier for the buyer and the seller who brought the car to the auction. Although all of the buyers at the auctions are used-car dealers, there is more diversity in the sellers. There are two major classes of sellers: car dealers and fleet/lease companies. A typical dealer sale might involve a new-car dealer bringing a car to auction that she received via trade-in and does not wish to (or cannot) sell on her own lot. The fleet/lease category includes cars from rental-car companies, university or corporate fleets, and cars returned to leasing companies at the end of the lease period. The important difference between these two types of sellers for our analysis is that the fleet/lease sellers tend to bring cars to the auction in large lots and set very low reservation prices whereas the dealers who sell cars at auction set higher reservation prices and sell a lower fraction of their cars. For the most part, therefore, there are fewer potential selection issues with cars brought to the auction by fleet/lease companies, which we investigate in robustness analyses for our regression results later in the paper.

A number of variables in the dataset are useful as outcomes in our analysis. The data report whether the car was sold and, if so, the sale price. There is also information on each car's condition. First, many 
cars are given a condition report by the auction company when they arrive on the lot. ${ }^{8}$ Second, for cars that arrive at the auctions early enough (often the fleet/lease cars), the auction company frequently generates an estimate of potential reconditioning expenses. We also have information on whether the car had known defects at the time of the auction. Cars run through the auction using a system of lights that signal the level of known defects with a car. A green light indicates that the car has no known major defects. When a car is assigned a yellow light, some specific defects are listed. A car that is assigned a red light may have some significant defects and is sold "as is." Finally, after the transaction, a buyer has the possibility of using an arbitration procedure offered by the auction company if they find major defects with the car that were not reported by the seller during the auction.

Crucial for this study, the data also report the Vehicle Identification Number (VIN) for each car. The 17-digit VIN of a car uniquely identifies a vehicle by its make, model, model year, body style, production year, production number on an assembly line, assembly plant, and, as indicated by the first digit of the VIN, the country where a car was assembled. For example, a number 1, 4, or 5 in the first digit of the VIN indicates that the car was assembled in the U.S. whereas the letter "J" indicates that it was assembled in Japan.

On the auction day, the VIN of the car is reported on a screen above the auction block along with a range of other information about the car. The used-car dealers bidding at the auctions could determine the country of assembly for a car by looking at the VIN number. For this reason, any differences we find in the average selling price of the cars assembled in different countries could reflect quality differences that the dealers observe at the auctions or their perceptions of the difference in value across country of production. Of course, if dealers systematically discount cars based solely on their observation of the country of assembly from the VIN number, and not from observed defects of the car, it must be that they anticipate lower value of those cars in the resale market. We focus on differences in value at the auctions and remain largely indifferent about the degree to which dealers are using direct information about the VIN in their auction purchase decisions. However, our anecdotal observations of the auction process and discussions with managers at the auction company do not give us any reason to suspect that dealers are systematically reacting to information in the VIN about the country of assembly. We also doubt that many retail used-car buyers look for this information because very few people are familiar with VIN decoding. For these reasons, we suspect that any differences we might observe in pricing

\footnotetext{
${ }^{8}$ Most of the cars that receive a condition report are those sold by fleet/lease sellers. Those sellers tend to bring their cars to the auction site days before the auction in a big lot, which allows time for the auction company to do an assessment of the car. The dealer-sellers often bring cars the morning of the auction and therefore rarely get a condition report from the auction company.
} 
dependent on the location of production reflect observable quality differences (e.g., rust, engine noise, worn interiors, etc.) of the car at the time of auction.

In order to perform a meaningful analysis of comparable cars, we isolate all vehicles that were assembled in both the U.S. and Japan as identified by make, model, model year, and body style. We limit the analysis to car types in which at least 5\% and no more than $95 \%$ of the cars were assembled in Japan. Because our analysis uses fine-grained fixed effects, we also limit our analysis to cars for which we have at least 20 observations of the same car in a given auction location and sold by the same category of seller (fleet/lease vs. dealer). We further focus on cars between 0 and 14 years of age and with at least 1,000 miles and less than 250,000 miles on the odometer.

Overall, the sample of multi-country models includes 565,652 cars. The vast majority of the cars are Hondas (37\%) and Toyotas (62\%). The fraction of cars assembled in Japan is approximately $26 \%$ and is nearly identical for both Honda and Toyota cars. The cars that appear most frequently in our data are Honda Accords and Toyota Camrys (both with four-cylinder engines).

Table 1 provides basic summary statistics. The average used car at an auction is just under 5 years old with a little less than 73,000 miles on the odometer. Approximately $64 \%$ of all cars brought to the auction sell, with an average selling price of roughly $\$ 8,545$. This table also shows how these basic summary statistics vary by whether the car was assembled in the U.S. or Japan. For most variables, there is little difference between the American and Japanese cars. In particular, once the sample is limited to comparable cars produced in both countries, the average price and quality are very similar, already suggesting a limited impact of the location of production. The slightly higher average price for cars produced in the U.S. is mainly due to the lower average age and mileage of U.S.-assembled cars (in the regressions below, when we control for these factors and add fixed effects, this difference will, in fact, reverse). A large difference that stands out in the raw data is that the Japanese cars are (not surprisingly) more likely to appear in auctions in western states. ${ }^{?}$

\section{Empirical Analysis}

Our goal is to assess whether the country of assembly of cars affects their long-term value differences. The challenge for this analysis is how to measure long-run quality and value since there is no simple onedimensional index of quality. Our baseline approach is to assess whether the prices of cars differ depending on whether they were produced in the U.S. or Japan holding all other relevant variables constant. Once we isolate a particular car type and control for key observables, such as mileage, the

\footnotetext{
${ }^{9}$ Of the states represented in the auction, we include AZ, CA, CO, HI, NV, NM, OR, UT, and WA as western states.
} 
variation in prices at the auction will reflect some combination of noise, local-market fluctuations, and any quality differences in the cars that are observable to the buyers at the auction. It is this last source of variation in which we are interested because it should reflect aspects of cars that are not captured in any quantitative datasets, such as visual appearance, engine noise, and rust.

We also assess the presence of value differences using five more direct measures of quality as outcome variables that are available in the dataset: whether the car was given a positive condition report by the auction company; the estimated cost to recondition the car provided by the auction company; whether the car was assigned a "green light" on the auction block, denoting no major defects; whether the car was sold at the auction; and whether an arbitration procedure was requested by the buyer after the car had been sold. The order in which we present these measures corresponds roughly to their relevant timing in the auction process. The condition report by the auction company and any reconditioning that the seller chooses to have performed are conducted prior to the auction. The light system, indicating defects, is displayed prominently for all cars that run through the auction blocks and provides perhaps the cleanest measure of known major defects for a car. ${ }^{10}$ Although visible defects should generally be priced into the car, a significant fraction of cars $(36 \%)$ fail to sell at the auction. This suggests that some problems with cars could lead to a failure to sell rather than simply a reduction in sale price. For this reason, we also use the information on whether the car sold as an indicator of quality. Finally, the company has an arbitration procedure to aid buyers who, after the car has been sold, find major defects that were not disclosed. We use data on the prevalence of arbitration as well.

The main hypothesis that we test is simple. If the country of production has a major effect on the value and quality of goods, then we should observe systematic differences in value and quality for otherwise identical goods produced in different countries. In the specific case of the automobile industry, if the perceived superiority of Japanese cars, as compared to American cars, is related to the production environment in Japan, then the vehicles produced by Japanese companies on the American soil should be of lower value and quality than the otherwise identical ones produced in Japan (for the U.S. market).

\subsection{Graphical analysis}

We begin our comparison of cars assembled in Japan with their U.S. counterparts with some simple graphs of average sale prices across a range of ages. First, Figure 2 plots the average prices for all cars in the sample of 565,652 vehicles, for different ages, splitting by country of assembly. The lines for

\footnotetext{
${ }^{10}$ The reasons that might cause a car to run under a yellow or red light would include transmission problems, exhaustsystem issues, structural damage from an accident, and so on.
} 
Japanese-assembled and U.S.-assembled cars lie on top of each other for the most part, and where differences exist, they are generally on the order of a $\$ 100$ premium for cars assembled in Japan. Second, in Figure 3, we further exploit the detail and size of our dataset to focus on the two most popular car models in our dataset. Panel A shows average prices for the Toyota Camry 4C 4D Sedan Le produced in $1999(N=47,804)$ and $2002(N=31,235)$ whereas Panel B shows average prices for the Honda Accord 4C 4D Sedan EX Auto again produced in $1999(N=17,907)$ and $2002(N=11,104)$. The price-by-age lines for the American and Japanese assembled cars are very close in all four cases across the full range of available ages. Interestingly, whereas for the two older models (1999) there seems to be a slight price premium for those assembled in Japan, the opposite is true for the newer models (2002), with the U.S.assembled models selling for slightly higher prices than the equivalent models assembled in Japan. This is particularly the case for the Toyota Camry. Taken together, these graphs provide our first suggestive evidence that there is very little difference in the prices of used cars based on location of assembly, and that, if any, the difference has decreased for more recent models.

\subsection{Regression analysis}

\subsubsection{Main price regressions}

We now estimate versions of the following model:

$$
\operatorname{PRICE}_{i j}=\alpha+\beta J A P A N_{i j}+f\left(X_{i j}\right)+\delta_{j}+\varepsilon_{i j}
$$

where $j$ indexes a particular "car type" and $i$ indicates individual observations of that car. The dependent variable in Equation (1) is the sale price conditional on selling. Depending on the specification, we use this variable in either levels or in natural logarithm. We regress prices on an indicator for whether the car was assembled in Japan $(J A P A N)$; thus our primary estimate of interest is $\hat{\beta}$. We control for characteristics of the individual car, denoted by the matrix $X_{i}$, such as a third-order polynomial in miles and the interaction of this polynomial with a car's age. ${ }^{11}$ Finally, and crucially for the inferences that we will be able to make, we include fixed effects for the car type, expressed by $\delta_{j}$ in Equation (1). Given the richness and size of our dataset, and to help us perform the best possible "apples-to-apples" comparison, the car type is defined at a very fine level. For all of our specifications, this car type includes the combination of make, model, body style, model year of the car, and auction year. ${ }^{12}$ Accounting for these

\footnotetext{
${ }^{11}$ On average (see Table 1), Japan-assembled cars have about 4,000 more miles and are about 3 months older. When running regressions of miles and age on the JAPAN dummy and car-type fixed effects, the differences (estimated parameter on Japan) reduce to less than 1,000 miles and just a few days.

${ }_{12}$ Because the fixed effect includes both the model year and the auction year, we cannot include a direct term for age among the controls in $X_{i}$.
} 
characteristics is important because models within the sample are produced in the U.S. and in Japan at different rates.

Table 2 reports the price-regression results. In Column (1), we include the basic fixed effect for car type in the regression, but do not control for auction location. The estimated price difference between Japan- and U.S.-produced cars is $\$ 125$, implying a price differential of about $2 \%$ on average. Not controlling for auction location, however, likely biases up the Japanese-U.S. price differential. Due to transportation costs, for any particular car model, the units assembled in Japan are more likely to be sold on the west coast than elsewhere in the country. This fact is relevant for our analysis because cars depreciate more quickly in places that have snowy winters (due to increased accidents and the use of road salt); therefore, used cars that are sold in the Midwest (where there is a greater concentration of U.S.-assembled models) will have lower value for reasons not related to the country of assembly of the car. More generally, there may also be different price levels in different local markets, which again could bias the results.

In the remaining columns of the table, and throughout the rest of the analysis, we include the auction location within our "car type" fixed effect. Adding that control in Column (2) reduces the Japan effect by about half, with the estimates showing that, all else equal, cars assembled in Japan sell for \$64 more than their U.S.-built counterparts. The estimate is statistically significant (not surprising with our large sample size) but modest in size when compared to the average sale price of $\$ 8,545$. The $95 \%$ confidence interval around the estimate (using robust standard errors clustered at the fixed-effect level) ranges from $\$ 48$ to $\$ 77$. In Column (3), we also add the seller type (dealer vs. fleet/lease) to the car-type fixed effect, and the estimate is essentially unchanged at $\$ 62$. Column (4) displays estimates from the same specification as in Column (3) but uses the natural log of price as the outcome variable. The estimates imply a price differential of about $1 \%$ on average. Given the size of the dataset, we can rule out at the $95 \%$ confidence level that this difference is more than $1.3 \%$.

\subsubsection{Quality-metrics regressions}

In Table 3, we consider the five variables of a car's quality described above and conduct essentially the same analysis that we did for prices:

$$
Y_{i i}=\alpha+\beta J A P A N_{i j}+f\left(X_{i j}\right)+\delta_{j}+\varepsilon_{i j},
$$

where $Y_{j}$ is, in turn, one of the five quality variables described above. In addition to providing additional metrics to evaluate the presence of systematic heterogeneities related to the location of production, the use of quality measures might also address some potential issues in the application and interpretation of the price results. First, the price regressions are based on only the sample of sold cars whereas, for some 
of the quality measures, we can use the full sample of sold and unsold vehicles, thus addressing some selection concerns (as further discussed below). Second, some of the quality metrics that we use (the condition report, the estimated reconditioning expenses, and the lights) are determined by the auction companies and are independent of some factors that might determine market prices in ways that might obscure value and quality difference. For example, imagine that there is a strong "brand effect," such that it is expected that final buyers only care about a car being of a certain make, and do not pay attention to some quality details. This might lead to compressing the price differential, but it would not affect the quality assessments made by the auction company.

With the exception of the estimated reconditioning costs, the other four outcome variables are dichotomous. In all cases, however, we use linear estimation rather than a discrete-choice model like Probit or Logit for the binary variables because we control for car types using a large number of fixed effects. ${ }^{13}$ The fixed effect $\delta_{i}$ that is used in these regressions is the combination of make, model, body style, auction year, model year, auction location, and seller type, as in Columns (3) and (4) of Table 2.

Although all of the point estimates go in the direction of higher quality for Japanese-assembled cars, we do not find any significant difference (either statistical or economic) in any of these outcome measures other than the probability of sale. The Japanese cars are 0.9 percentage points more likely to sell at auction than are their U.S.-assembled counterparts, but again this is a modest difference compared with the baseline probability of selling of $64 \%$.

\subsubsection{Robustness tests for average differences}

The findings reported above indicate that "otherwise identical" cars produced in Japan and the U.S. do not, on average, have major value differences. In this section, we investigate whether these results are robust to potential alternative explanations and specifications that would, instead, indicate a larger role for the country of production in ways that our baseline empirical strategy does not capture.

Selection issues. One potential concern with the price regressions is that they are based on cars that eventually sold at an auction. Cars that go unsold might be of systematically low quality. If these lowquality cars were disproportionally assembled in one of the two countries, then the estimates in Table 2 might not be reliable. However, the fact that there are very small differences in selling probability between cars assembled in the U.S. and Japan is reassuring that the price regressions described in the previous section are not substantially affected by this type of selection bias. Note also that, in the

\footnotetext{
13 Because reconditioning occurs almost exclusively for cars brought to auction by fleet/lease sellers (who bring the cars several days in advance providing time for reconditioning), we also ran the analysis for estimated reconditioning costs limiting the sample to the fleet/lease cars, and the findings did not change.
} 
regressions reported in Table 3, where we analyze direct quality measures, in all cases except for the probability of arbitration, the models are estimated on the full sample of both sold and unsold cars (the sample is smaller when we use the green light indicator because this variable was recorded only from 2005 on), and no differences are found. ${ }^{14}$

Somewhat more fundamentally, our sample is selected in that cars brought to auction are not necessarily representative of all used cars transacted in different markets. Not all used cars go through the wholesale auction process, and it may be that quality (either good or bad) is a driver of whether cars appear at the auction in the first place. This presents a potential challenge to the external validity of our results. For example, suppose that only very low-quality cars are transacted at wholesale auctions. This would lead us to find only small differences in quality by country of production even if there were large differences in the universe of used cars. One way that we can address this concern is to exploit the differences in behavior between our different seller types. Recall that the fleet/lease sellers (e.g., rentalcar companies) tend to sell their entire aging fleets in large lots at the auctions. There is plausibly very little or no selection in the cars that these sellers bring. On the other hand, the dealer sellers have a fair amount of discretion on which cars they bring to auction rather than selling on their own lots. Columns (1) through (4) of Table 4 report estimates from the same specification as in our preferred specification from Columns (3) and (4) of Table 2, with the sample of sold cars broken into fleet/lease sellers and dealer only sellers. The differences between U.S.- and Japan-assembled cars are somewhat larger for the fleet/lease sellers, but this is mostly due to the higher average prices for the fleet/lease cars (they tend to be younger and with lower mileage). The log difference between U.S.- and Japan-assembled vehicles is estimated to be the same for fleet/lease and dealer cars. Furthermore, when we look at the probability that a car was built in Japan (not reported here), we find that there is very little difference between the probability for fleet/lease versus dealer cars.

Another approach to explore whether selection on which cars appear at wholesale auctions could be affecting our results is to compare the distribution of country of assembly in our auction data to the fraction produced in each country when the cars were sold new. Although the auction locations for this company do not cover the country in a representative fashion, given the large scale of the auction data here, we could expect that, in the absence of quality selection into the auction, the distribution at the auctions would roughly match the production data. However, if only low-quality cars are brought to auction and there are systematic differences in quality by country-of-assembly, then the ratios of Japanese to U.S. cars should be different in the auction data than in the underlying production runs for the cars. To address this issue, we collected data from Ward's Automotive Yearbook, a leading automobile

\footnotetext{
${ }^{14}$ The estimates on the sample of only sold cars are very similar to those on the full sample, for all of these variables.
} 
trade publication, on the fraction of new-car sales in North America that were imports (i.e., assembled in Japan) versus domestically produced by make, model, and model year for the cars in our sample. In Figure 4, we graph the fraction of cars for each model that were assembled in Japan in the auction data against the fraction imported from Japan based on the new-sales data from $W$ ard's Automotive Yearbook. Our data are quite closely related to the fraction of imports when cars were new. In particular, the scatter of points is not systematically shifted on one side of the 45-degree line or the other, suggesting that there is no strong country-of-assembly selection bias in which cars come to the auction. In fact, a regression of the relationship (with a constraint to pass through the origin) has a coefficient of 1.05.

This comparison with production statistics also gives us another robustness test for our price regressions. If selection is a concern, we would expect our results to change if we focused only on models for which the country-of-assembly fractions at the auctions were similar to those from the production data. In Columns (5) and (6) of Table 4, we estimate our basic price regressions, excluding from the sample the car models for which the difference in fraction of imports between our data and the Ward's data is greater, in absolute value, than 15 percentage points. This cut does not change the results we saw for the full sample. ${ }^{15}$ These findings suggest that substantial differential selection into the auctions by country of production is unlikely to be a problem for our analysis.

It is also possible to use the Ward's data to do a Heckman-style correction. We do not have any information for cars at the individual level that would allow us to estimate the first-stage in a Heckmancorrection model for the probability of being observed in the auction dataset. However, the $W$ ard's data does allow us to estimate, for each make/model/model-year combination (e.g., 1999 Honda Accord), the fraction of cars assembled that year in each country that eventually appear in our auction data. Those fractions give us an estimate of the probability that particular car models assembled in each country will be observed in the auction dataset and is roughly analogous to the first-stage estimates in a Heckman procedure. We can then use those probabilities of being observed to create an inverse Mills ratio (at the make/model/model-year by country-of-assembly level) and include that in our main regression specifications. We find that including the inverse Mills ratio generates a modest increase in the size of the Japan coefficient in our regressions, but Japanese difference is still consistently within the $\$ 100$ range and none of the results change in a qualitatively meaningful way when including this correction procedure.

15 The "outliers" are the 1987, 1993, 1997, 1998, and 2000 models of the Honda Civic; the 1990 and 2001 Honda Accord; and the 2006 Toyota Camry. Note that in our sample, there also are some car models for which there is no information in the $W$ ard s data. If we also exclude these models with no information in the $W$ ard's data, the estimates do not significantly change (the estimate on the $J A P A N$ dummy is \$57). 
Under-specification and specific car options. Although we control for very granular fixed effects, our comparisons might still suffer from omitted variable bias. First, because the quality measures that we used in Table 3 as outcome variables are likely to also affect a car's price, we might want to include them in the price regressions. We do so in Column (7) of Table 4 and find very similar results to those in Table 2: $0.8 \%$ versus $1 \%$. As it turns out, the slightly lower Japan estimate when controlling for quality measures does not actually come from the inclusion of quality controls. Information on the light-code for the car is available only after 2005 in our data. If we limit the sample to auctions from 2005 on, the estimated Japan difference is $0.8 \%$ whether or not we control for quality measures.

A second concern might be that, despite our fine-level fixed effect, there could be systematic variation in the features included in models assembled in the U.S. versus Japan. Unlike American automakers, who during this period gave customers numerous options, Honda and Toyota are wellknown for producing a limited number of trim levels for a car and avoiding optional features. Therefore, hidden features are unlikely to be a large issue here. However, we do have some limited information about optional features that the auction company started recording for auctions conducted in 2006 and later. In Column (8), we add indicators for a range of car features, such as sunroof, anti-lock brakes, automatic windows, etc. Adding these controls results in a coefficient estimate of $0.9 \%$ in the $\log$ specification, again not distinguishable from our original estimate.

Residual variation. One might also be concerned that the high $R$-squared values in our price regressions imply that there is little variation in auction prices once the basic observables have been controlled for, and that this is the reason why we find only modest differences between Japanese and U.S. cars. For instance, imagine that, for efficiency reasons, dealers bought used cars based on an explicit formula that used inputs of the car type and mileage and ignored all other observations about the car. In such a setting, even if there were underlying differences in value due to the country of production, the market would not be pricing them in, and the absence of a difference in value related to the country of production would not emerge in our analysis. We are not concerned, however, that this is the situation with these used-car auctions. First, variables such as a poor condition report or defects listed in the light system have very large estimated impacts on prices. For example, all else equal, a car listed with a red light sells for a significant $\$ 853$ less than one running under a green light (the difference between a yellow light and a green light is $\$ 575$ ); each dollar expected to be spent for reconditioning translates into a price reduction of $\$ 0.4$. In addition, the residuals from a regression specification such as that in Column (2) in Table 2, dropping the Japanese dummy, range by over $\$ 2,100$ from the $10^{\text {th }}$ to $90^{\text {th }}$ percentiles, suggesting that there is significant variation in auction prices that is not captured by controlling for car characteristics and local-market conditions. 
Differences across the value distribution. The analyses above are conducted on means. When considering the formation of perceptions of long-run quality, however, it may also be worth looking at the extremes of the value distribution. In particular, it could be that the chance of buying a car of very low value is what most significantly influences perceptions of long-run quality. To the extent that cars whose value is in the left tail of the distribution are disproportionately produced in one country (for example, in the U.S.), an analysis based also on mean values might obscure this effect. To investigate this possibility, we consider the estimated Japanese-U.S. differences at different quantiles of the price distribution. To handle the large number of fixed effects in our analysis, we employ the following procedure. First, for each car type (defined by the combination of make, model, body style, model year, auction year, and auction location), we estimate parameters from the following specification:

$$
\operatorname{PRICE}_{i j}=\gamma_{\theta} J A P A N_{i j}+f_{\theta}\left(X_{i j}\right)+u_{\theta i j} ; Q_{\theta}\left(\operatorname{PRICE}_{i j} \mid J A P A N_{i j}, \operatorname{miles}_{i j}\right)=\gamma_{\theta} J A P A N_{i j}+f_{\theta}\left(X_{i j}\right),
$$

where $j$ is each specific car type and the estimates are made at the $\theta^{\text {th }}$ quantile; where $\theta \in\{0.1,0.25 .0 .5,0.75,0.9\} ; f_{\theta}\left(X_{i j}\right)$ is a third-order polynomial in miles, with the parameters allowed to differ at each quantile $\theta$. Then, for each $\theta$, we compute the weighted average of $\hat{\gamma}_{\theta}$ over all car types $j$, with the weight being the relative sample size of each car type (number of observations over total number of observations). We limit the analysis to car types for which we have at least 20 vehicles sold. We use a bootstrap procedure (with 200 replications) to estimate the standard errors of these weightedaverage regression estimates. The results are reported graphically in Figure 5, and compared to the OLS parameter estimate on $J A P A N$ (the standard errors for the OLS estimates are derived from a bootstrapping procedure like the one described above).

There is a slightly higher estimate of the difference between Japan- and U.S.-assembled cars for the lower percentiles, indicating that prices might be picking up some differences for cars of lowest values, and the differences are smaller for high-percentile values. Overall, however, these quantile estimates are comparable to the average OLS results.

\subsubsection{Exploring heterogeneity across makes and over time}

The results presented above focus on the average difference between Japanese- and U.S.-assembled cars in our dataset. Although we document modest average differences, those averages may obscure important heterogeneity across car makers (Honda and Toyota) or over time. We now explore that variation in more depth. In addition to being a further test of the robustness of our findings, this analysis addresses questions that are interesting on their own. First, Honda and Toyota might have followed different patterns in their process of transferring their practices from Japan to the U.S. While sharing a few common aspects, important differences in the production processes at Honda and Toyota plants 
have been documented (Russ, 2009; Sako, 2004); these differences might also have affected each company's ability to achieve similar levels of quality in different countries. To our knowledge, this possibility has not been explored through large-sample empirical analyses to date. Differences in value and quality convergence between the two carmakers might also be due to the simple fact that Honda set its first plant in the U.S. 6 years before Toyota started production at the Georgetown, KY plant (where the most popular Toyota model, the Camry, is assembled). Therefore, a simple "learning by doing" story would imply that the longer period that the car has been available (and the higher the cumulative production), the more successful the application of high-quality production processes would be. ${ }^{16}$ Second, and relatedly, it is reasonable to assume that, if any quality differences existed, they were more likely to occur in the first years of operations of the overseas plants. Third, by having information for each model year, we can analyze whether any convergence in the ability to produce high-quality cars occurred gradually or through a more "discrete" pattern.

In Table 5, we repeat our main regression analysis, but split the sample into Toyota and Honda cars. Comparing Columns (1) and (5), we see that the Japanese-assembled Toyotas have average sale prices $\$ 99$ higher than their American-assembled counterparts. The Hondas produced in Japan, however, sell for only a statistically insignificant $\$ 7$ more than the U.S.-built Hondas. Thus, we see that all of the Japanese-U.S. differences that have been observed above come from Toyota cars.

In Figure 6, we explore the estimated Japanese-U.S. differences for different model years of the two most popular cars in the dataset: the four-cylinder versions of the Toyota Camry and the Honda Accord, which represent about $84 \%$ of the full dataset. Panel A plots the estimated coefficients from our basic log-price regression specification by model year for the Toyota Camry and gives the 95\% confidence interval around the estimates. Camrys produced before 2001 have somewhat sizeable estimated differences between Japan-assembled and U.S.-assembled cars (2-3\%). As of 2002, however, that Japanese-assembly advantage disappears and, in fact, reverses, with Camrys assembled for the 2002 model years and later showing average differences in favor of the U.S.-assembled cars of around 1\%. Interestingly, over this period, Toyota engaged in substantial redesigns of the Camry every 5 years and the break in the series at 2002 coincided with a new version of the Camry that was launched for the 2002 model. For the Honda Accord, the patterns are more stable. For models produced prior to 1995, there is a large estimated log-price difference on the order of 3-4\%, but these estimates are not precise and the 95\% confidence interval includes 0 for many of these model years. For model years 1999 and on, for which the estimates are very precise, there is essentially no difference between the Japan-assembled and U.S.-assembled Honda models.

${ }^{16}$ Levitt, List and Syverson (2012) have recently explored learning by doing in an auto assembly plant. 
These time patterns for Toyota and Honda are detailed in Columns (2), (4), (6), and (8) of Table 5 where we include an interaction between the $J A P A N$ dummy and an indicator for model years prior to 2002. For Toyota models produced after 2002, the American-built cars have predicted sale prices $0.7 \%$ higher whereas those produced before 2002 show a 2\% advantage over the Japanese-assembled cars. For Honda, there is no difference estimated for recent models and a modest $0.7 \%$ estimated difference for models produced prior to 2002. Similar results are found when looking at the other quality metrics (Table 6). In particular, the slightly higher sales probability for Japanese cars is driven by pre-2002 Toyota models.

Figure 7 offers our most detailed investigation into the heterogeneity in Japanese-U.S. production differences. The graphs plot the estimated Japan-U.S. difference from our standard log-price regression specification, but now run separately by four Camrys and Accords by model year and including interactions between the Japan dummy and the age of the car. ${ }^{17}$ Each line in these graphs represents a different model year (labels shown at the right end of the line) with estimates of the Japan coefficient for each age of that model year observed in the auction data. ${ }^{18}$ Panel A shows the results for the fourcylinder Toyota Camry and Panel B the results for the four-cylinder Honda Accord. These graphs largely confirm the patterns from Figure 6. In particular, there is a clear break in the level of the Japanese-U.S. difference between the 2001 and 2002 model years for the Toyota Camry whereas the Honda Accord only shows sizeable differences for very old cars in the dataset. Looking at the slopes of the lines, however, reveals some new information. For Toyota Camrys produced prior to 2002, most of the lines are quite flat, suggesting that the log-price differentials in favor of the Japanese-assembled cars had appeared within the first couple years of the cars' lives and that the differences (in percentage terms) persist as these cars age. For the Honda Accord, we see little difference for cars that are roughly 8 years old or younger. For older cars, however, there is at least the suggestion of a positive slope to these lines. Because estimates for very old cars are noisy, we are cautious in interpreting these differences, but to the extent that they exist, they might be consistent with some quality differences that increase in favor of the Japanese-assembled models as the cars become very old.

\section{Discussion and Conclusion}

In this paper, we use a dataset with information on over 565,000 used automobiles brought to wholesale auctions to examine whether the prices of "otherwise identical" Japanese-make cars (i.e., cars of the same

${ }^{17}$ We account for body-style in these price regressions but estimate the Japan differences aggregated across body styles for that make and model year (i.e., without interactions with body style).

${ }^{18}$ For example, if we take the case of the 1999 Toyota Camry, we observe those cars at ages 3-9 in our auction data that run from 2002-2008. 
make, model, model year, and body style that were transacted in the same year at the same auction site where they were brought by the same type of seller) vary depending on whether the car was assembled in the U.S. or Japan. We find that on average the Japanese-assembled versions sell for slightly more than their U.S.-built counterparts. For recent model years, we find no advantage for the Japanese-built cars whereas for older model years, especially for Toyota models produced prior to 2002, there are somewhat more substantial differences.

Despite the large sample size, our ability to control for observables and very fine-grained car fixed effects, and the several robustness checks we performed, there are perhaps a few other issues that could affect the interpretation of our results that are worth discussing. For example, we do not have direct information on production costs. It is possible that the broad similarities in the outcome measures we observe (especially for recent model years) might hide differences on the input side. However, previous studies, such as Pil and MacDuffie (1999), have documented that input costs (and also, for example, investments in safety) in Japanese plants and in the U.S. transplants are highly comparable. Also, we cannot account for some specific tastes of final users that might be related to the country of assembly of a car. American consumers might put a premium on buying vehicles actually produced in the U.S. Such a preference might lower the price of Japanese-assembled cars and thereby counteract a higher premium that would otherwise be associated with Japanese-built cars because of built quality. Although we cannot rule out such an effect, as mentioned above, customers typically do not know how to decode VINs and are unlikely to actually know where their Japanese brand car was assembled. Our analysis of direct quality measures also suggests that this type of story is unlikely to be affecting our results. The quality assessments are made, for the most part, by the auction company and prior to the transactions occurring, and we find no meaningful differences (on average) related to the country of assembly.

Overall, we see our findings as largely consistent with the idea that the two dominant Japanese automakers have been successful in transferring their high-quality production to their U.S. transplants. The fact that Japanese car companies have been largely successful at exporting their organizational capital might also indicate an overall ability to export capital in general, and, for this reason, our results may inform the debate on the trade-offs between importing labor and exporting capital in response to demographic changes (Higgins and Williamson, 1997; Yashiro, 2001).

Our findings about Toyota, however, also suggest that this ability to transfer quality production is not automatic. Our estimates imply that for cars built through 2001, the U.S.-assembled Toyotas had somewhat lower long-run quality than did their Japanese-assembled counterparts. When one considers that Honda established its first plant in the U.S. about 5 years before Toyota did, the fact that Honda 
seems to have had a better convergence in the U.S. and Japanese build quality might be consistent with a "learning by doing" story. ${ }^{19}$ Yet, by 2000, Toyota had been building the Toyota Camry in Kentucky for 12 years. The fact that the U.S.-built Camrys manufactured at that time show 2-3\% lower resale values than do the Japanese-built ones suggests that convergence in practices is not always complete, even for highly successful and well-run firms like Toyota. The fact that these resale-value differences shifted abruptly with the overhaul of the design of Toyota's flagship car for 2002 also seems significant. This result suggests to us that convergence in production practices (or at least production quality) may be difficult to achieve through gradual incremental change and may instead require larger changes to production and management practices, similar to what a plant would see when launching a fully redesigned product. Of course, our study-based as it is on observing used-car transactions—cannot speak to the sources of these management and production changes, or to the specific origins of the different patterns for Honda and Toyota. ${ }^{20}$ Our hope is that our observations here may generate an interesting avenue of exploration for management scholars.

This research has clear implications for understanding the ability of the Japanese automakers to transfer their techniques to foreign plants. But what, if anything, do these results have to say about the crisis in American auto manufacturing and the perceived quality gap between American and Japanese cars? We believe that our evidence is most consistent with the interpretation that if U.S. car makers struggle to produce cars of comparable quality to their foreign competitors, that competitive disadvantage is unlikely to be primarily a result of location-specific factors, such as worker ability, available supplier networks, and general American "work culture." Any disadvantage is more likely to stem, instead, from company-specific factors, such as design and management practices defined at the corporate level. The one obvious caveat, however, is that the Japanese plants we observe are not unionized whereas workers are generally unionized at the production plants of the American automakers. Although our results cannot speak one way or another to whether unionization affects production quality for the American automakers, they do clearly show that there is nothing inherently or fundamentally limiting in the American manufacturing environment that prevents quality automobile production. ${ }^{21}$

The apparent limits of Toyota's ability to fully transfer its production quality to its U.S. plants for at least part of the 1990s may also speak to the challenges that car companies face in trying to adopt improved production practices. Our findings are an example of replication within plants of the same

\footnotetext{
${ }^{19}$ Honda had also set a motorcycle assembly plant in the U.S. in the late 1970s. On the other hand, Toyota had some previous experience with production in the U.S. through the NUMMI (Russ, 2009).

${ }^{20}$ Russ, 2009 and Sako, 2004 explore the managerial and cultural differences of Honda and Toyota.

${ }^{21}$ For recent discussions on producing high-quality manufacturing in the U.S., see for example: Engardio (2009); Helper, Krueger and Wiel, 2012; National Economic Council, 2011; and Porter and Rivkin, 2012.
} 
company (in different countries), but are consistent with the notion that replication is potentially very different from imitation between competitors (Gibbons and Henderson, 2012; Rivkin, 2001; Szulanski, 1996), as witnessed by the persistent depreciation gap documented in Figure 1 between cars of American and Japanese makers. If Toyota struggled somewhat to fully incorporate its practices at its own plants in the U.S., then it is perhaps less surprising that the American automakers struggled throughout this period to adopt the successful practices of their Japanese competitors.

Finally, we feel that our use of a large auction dataset in this analysis represents a useful methodological contribution to the broad literature on productivity. Auction settings offer highfrequency data and information from competitive markets where prices are highly informative of all of the (observable) characteristics of a product. In wholesale auctions, in particular, both the demand and supply side are composed of sophisticated agents with knowledge and experience on how to "correctly" value different attributes of a good. Analyzing these types of data to better understand production value, especially for aging durable goods, should be a promising direction for future work in this vein. For example, auction outcomes could provide a "laboratory" for additional studies of how otherwise identical products differ in quality according to their location of production. This would be particularly interesting because firms from large emerging economies, such as China and India, are gaining a foothold in international markets (and, vice versa, Western multinationals are increasingly producing in plants in these and other emerging countries). The approach in this paper could also be used to study differences across identical products manufactured in multiple plants within a country; this could provide a means for assessing questions such as plant-specific quality, the role of local/regional factors (see, for example, Shaver and Flyer, 2000 on geographic clustering and performance of foreign greenfield investments in the U.S.), as well as the effect of events such as labor disputes and unrest (see, for example, Mas, 2008). 


\section{References}

Abo, Tetsuo (ed.). 1994. Hybrid Factory: The Japanese Production System in the United States. New York: Oxford University Press.

Aghion, Philippe and Peter Howitt. 2009. The Economics of Growth. MIT Press.

Argote, Linda, and Dennis Epple. 1990. "Learning Curves in Manufacturing." Science, 247(4945): 920-924.

Barber, Brad M., and Masako N. Darrough. 1996. "Project Reliability and Firm Value: The Experience of American and Japanese Automakers, 1973-1992.” Journal of Political Economy, 104(5): 1084-1099.

Barrell, Ray and Nigel Pain. 1999. "European Growth and Integration: Domestic Institutions, Agglomerations and Foreign Direct Investment in Europe." European Economic Review, 43: 925 -935.

Bartelsman, Eric J., Jonathan Haskel, and Ralph Martin. 2008. "Distance to Which Frontier? Evidence on Productivity Convergence from International Firm-level Data." CEPR Discussion Paper no. 7032.

Beechler, Schon, and John Z. Yang. 1994. "The Transfer of Japanese-Style Management to American Subsidiaries: Contingencies, Constraints, and Competencies.” Journal of International Business Studies, 25(3): 467-491.

Bloom, Nicholas, Raffaella Sadun, and John Van Reenen. 2012. "Americans Do I.T. Better: U.S. Multinationals and the Productivity Miracle." American Economic Review.

Chung, Wilbur, Will Mitchell, and Bernard Yeung. 2003. "Foreign Direct Investment and Host Country Productivity: The American Automotive Component Industry in the 1980s." Journal of International Business Studies, 34(2): 199-218.

Council of Competitiveness and Deloitte. 2010. Global Manufacturing Competitiveness Index.

Cusumano, Michael A., 1988. "Manufacturing Innovation: Lessons from the Japanese Auto Industry." Sloan Management Review, October 15.

Dassbach, Carl H. A. 1994. "The Japanese World of Work and North American Factories." Critical Sociology, 20(1): 3-30.

Dertouzos, Michael L., Richard K. Lester, and Robert M. Solow. 1989. Made in America. Harper Perennial.

Doeringer, Peter B., Edward Lorenz, and David G. Terkla. 2003. "The adoption and diffusion of highperformance management: lessons from Japanese multinationals in the West." Cambridge Journal of Economics, 27(2): 265-286

Dore, Ronald, and Mari Sako. 1998. How the Japanese Learn to Work. New York: Routledge.

Engardio, Pete. 2009. "Can the Future Be Built in America?” Business Week, September 10.

Freeman, Richard and Kathryn Shaw (eds.). 2009. International Differences in the Business Practices and Productivity of Firms. University of Chicago Press.

Fucini, Joseph J., and Suzy Fucini. 1990. Working for the Japanese: Inside Mazda's American Auto Plant. New York: Free Press.

Fujimoto, Takahiro. 2000. "Shortening lead time through early problem solving - A new round of capability building in the auto industry." In Jurgens, U. (ed.) New Product Development and Production Networks. Berlin, Springer.

Gertler, Meric S. 2001. "Best practice? Geography, learning and the institutional limits to strong convergence." Journal of Economic Geography, 1(1): 5-26.

Gibbons, Robert, and Rebecca Henderson. 2012. "Relational Contracts and Organizational Capabilities." Organization Science.

Graham, Laurie. 1995. On the Line at Subaru-Isuzu: The Japanese Model and the American Worker. Ithaca, NY: Cornell University Press

Grossman, Gene M., and Giovanni Maggi. 2000. "Diversity and Trade." American Economic Review, 90(5): 12551275.

Hashimoto, Masanori. 1994. "Employment-Based Training in Japanese Firms in Japan and in the United States: Experiences of Automobile Manufacturers." In Lisa M. Lynch (Ed.), Training and the Private Sector (pp. 109-148). Chicago, IL: University of Chicago Press. 
Hayes, Robert H., and Kim B. Clark. 1985. "Exploring the Sources of Productivity Differences at the Factory Level.” In K. B. Clark, R. H. Hayes, and C. Lorenz (Eds.), The Uneasy Alliance: Managing the Productivity-Technology Dilemma. Boston, MA: Harvard Business School Press.

Helper, Susan. 1991. "Strategy and Irreversibility in Supplier Relations: The Case of the US Automobile Industry." Business History Review, 65(4): 781-824.

Helper, Susan, Timothy Krueger, and Howard Wiel. 2012. "Why Does Manufacturing Matter? Which Manufacturing Matters?" Brookings Institution - Metropolitan Policy Program, February.

Helpman, Elhanan, Marc J. Melitz, and Stephen R. Yeaple. 2004. "Exports versus FDI with heterogeneous Firms." American Economic Review, 94(1): 300-316.

Higgins, Matthew, and Jeffrey G. Williamson. 1997. "Age Structure Dynamics in Asia and Dependence on Foreign Capital." Population and Development Review, 23(2): 261-293

Hofstede, Geert. 1984. Culture's Consequences: International Differences in Work-Related Values. Beverly Hills, CA: Sage Publications.

Ichniowski, Casey, Kathryn Shaw and Giovanna Prennushi. 1997. "The Effects of Human Resource Management Practices on Productivity: A Study of Steel Finishing Lines." American Economic Review, 87(3): 291-313.

Ingrassia, Paul and Joseph B. White. 1994. Comeback. The Fall and Rise of the American Automobile Industry. Simon and Schuster.

JD Power and Associates, 2010: Initial Quality Study.

Jovanovic, Boyan. 1982. "Selection and the Evolution of Industry," Econometrica, 50(3), 649-70

Kenney, Martin, and Richard Florida. 1995. "The Transfer of Japanese Management Styles in Two US Transplant Industries: Autos and Electronics." Journal of Management Studies, 32(6): 789-802.

Khanna, Tarun and Jan W. Rivkin. 2001. "Estimating the Performance Effects of Business Groups in Emerging Markets." Strategic Management Journal, (22): 45-74

Klier, Thomas, and James Rubenstein. 2008. Who Really Made Your Car?: Restructuring and Geographic Change in the Auto Industry. Kalamazoo, MI: W.E. Upjohn Institute for Employment Research.

Leibenstein, Harvey. 1987. Inside the Firm: The Inefficiencies of Hierarchy. Cambridge, MA: Harvard University Press.

Levitt, Steven, John List, and Chad Syverson. 2012. "Towards an Understanding of Learning by Doing." University of Chicago working paper.

Liker, Jeffrey K., W. Mark Fruin, and Paul S. Adler (Eds.). 1999. Remade in America: Transplanting and Transforming Japanese Management Systems. New York: Oxford University Press.

Lippman, Steven A. and Richard P. Rumelt. 1982. "Uncertain Imitability: an Analysis of Interfirm Differences in Efficiency. Under Competition.” Bell Journal of Economics, 13: 418-438

Lowe, James, Jonathan Morris, and Barry Wilkinson. 2000. "British Factory, Japanese Factory and Mexican Factory: An International Comparison of Front-Line Management and Supervision." Journal of Management Studies, 37(4): 541-562.

Makino, Shige, Takehiko Isobe, and Christine M. Chan. 2004. "Does Country Matter?" Strategic Management Journal, 25: 1027-1043.

Mas, Alexandre. 2008. Labor Unrest and the Quality of Production: Evidence from the Construction Equipment Resale Market. Review of Economic Studies, 75(1): 229-258.

McGahan, Anita M., and Michael E. Porter. 1997. "How Much Does Industry Matter, Really?” Strategic Management Journal, 18(S1): 15-30.

McGahan, Anita M., and Michael E. Porter. 1999. “The Persistence of Shocks to Profitability.” Review of Economics and Statistics, 81(1): 143-153.

McGahan, Anita M., and Rogerio Victer. 2010. "How much does home country matter to corporate profitability?" Journal of International Business Studies, 41: 142-165.

National Economic Council. 2011. A Strategy for American Innovation: Securing Our Economic Growth and Prosperity.

Nelson, Richard R. and Sydney Winter. 1982. An Evolutionary Theory of Economic Change, Belknap Press.

Pil, Frits K., and John P. MacDuffie. 1999. "What Makes Transplants Thrive: Managing the Transfer of 'Best Practice' at Japanese Auto Plants in North America.” Journal of World Business, 34(4): 372-391. 
Pisano, Gary and Willy Shih. 2009. "Restoring American Competitiveness." Harvard Business Review, July-August.

Porter, Michael. 1998. The Competitive Advantage of Nations. Free Press.

Porter, Michael and Jan W. Rivkin. 2012. "Choosing the United States." Harvard Business Review, March.

Redding, Stephen J. 2011. "Theories of Heterogeneous Firms and Trade." Annual Review of Economics, forthcoming.

Rivkin, Jan W. 2001. "Reproducing Knowledge: Replication without Imitation at Moderate Complexity." Organization Science, 12(3): 274-293.

Rumelt, Richard P. 1991. “How Much Does Industry Matter?” Strategic Management Journal, 12(3): 167-185.

Russ, Jonathan R., 2009. Global Motivations. Honda, Toyota and the Drive toward American Manufacturing. University Press of America.

Sako, Mari. 2004. "Supplier Development at Honda, Nissan and Toyota: Comparative Case Studies of Organizational Capability Enhancement.” Industrial and Corporate Change, 13(2): 281-308.

Sako, Mari and Susan Helper. 1998. "Determinants of Trust in Supplier Relations: Evidence from the Automotive Industry in Japan and the United States." Journal of Economic Behavior \& Organization, 34(3): 387-417.

Schmalensee, Richard. 1985. "Do Markets Differ Much?” American Economic Review, 75(3): 341-351.

Shaver, J. Myles and Fredrick Flyer. 2000. "Agglomeration Economies, Firm Heterogeneity, and Foreign Direct Investment in the United States.” Strategic Management Journal, 21(2): 1175:1193.

Shibata, Hiromichi. 2001. "Productivity and Skill at a Japanese Transplant and Its Parent Company." Work and Occupations, 28(2): 234-260.

Shimokawa, Koichi. 2010. Japan and the Global Automotive Industry. New York: Cambridge University Press.

Syverson, Chad. 2004. "Product Substitutability and Productivity Dispersion." Review of Economics and Statistics, $86(2): 534-550$.

Syverson, Chad. 2011. "What Determines Productivity?” Journal of Economic Literature, 49(2), 326-65.

Szulanski, Gabriel. 1996. "Exploring Internal Stickiness: Impediments to the Transfer of Best Practice Within the Firm." Strategic Management Journal, 17(S2): 27-43.

Train, Kenneth E., and Clifford Winston. 2007. "Vehicle Choice Behavior and the Declining Market Share of U.S. automakers." International Economic Review, 48(4):1469-1496.

Van Reenen, John. 2010. White Paper for NSF Grand Challenges.

Womack, James P., Daniel T. Jones, and Daniel Roos. 1990. The Machine that Changed the World. New York: Rawson Associates.

Yashiro, Naohiro. 2001. "Social Implications of Demographic Change in Japan." In Seismic Shifts: The Economic Impact of Demographic Change (eds. Jane Sneddon Little and Robert K. Truest), Federal Reserve Bank of Boston.

Yates, Brock W. 1983. The Decline and Fall of the American Automobile Industry. New York: Empire Books. 


\section{Figure 1: Resale values by car age for Japanese vs. U.S. automakers}

This figure graphs the average estimated resale value for the top 45 car models produced by either American or Japanese car manufacturers that appear in the wholesale auction sample between 2002 and 2008. For cars sold during the same year as their listed model year, the estimate is based on a representative car with 10,000 miles on the odometer. Each subsequent year increases the mileage by 14,000. The figure plots the ratio of the estimated price for cars of that age and mileage as a fraction of the estimated "near new" value for that car at 0 years and 10,000 miles. Estimates are obtained separately for each car model (e.g., Ford Taurus or Honda Accord) from regressions that control for fourth-order polynomials in age and mileage as well as fixed effects for body style and auction location. The curves here are the weighted average of these depreciation curves for the cars produced by automakers from the respective country.

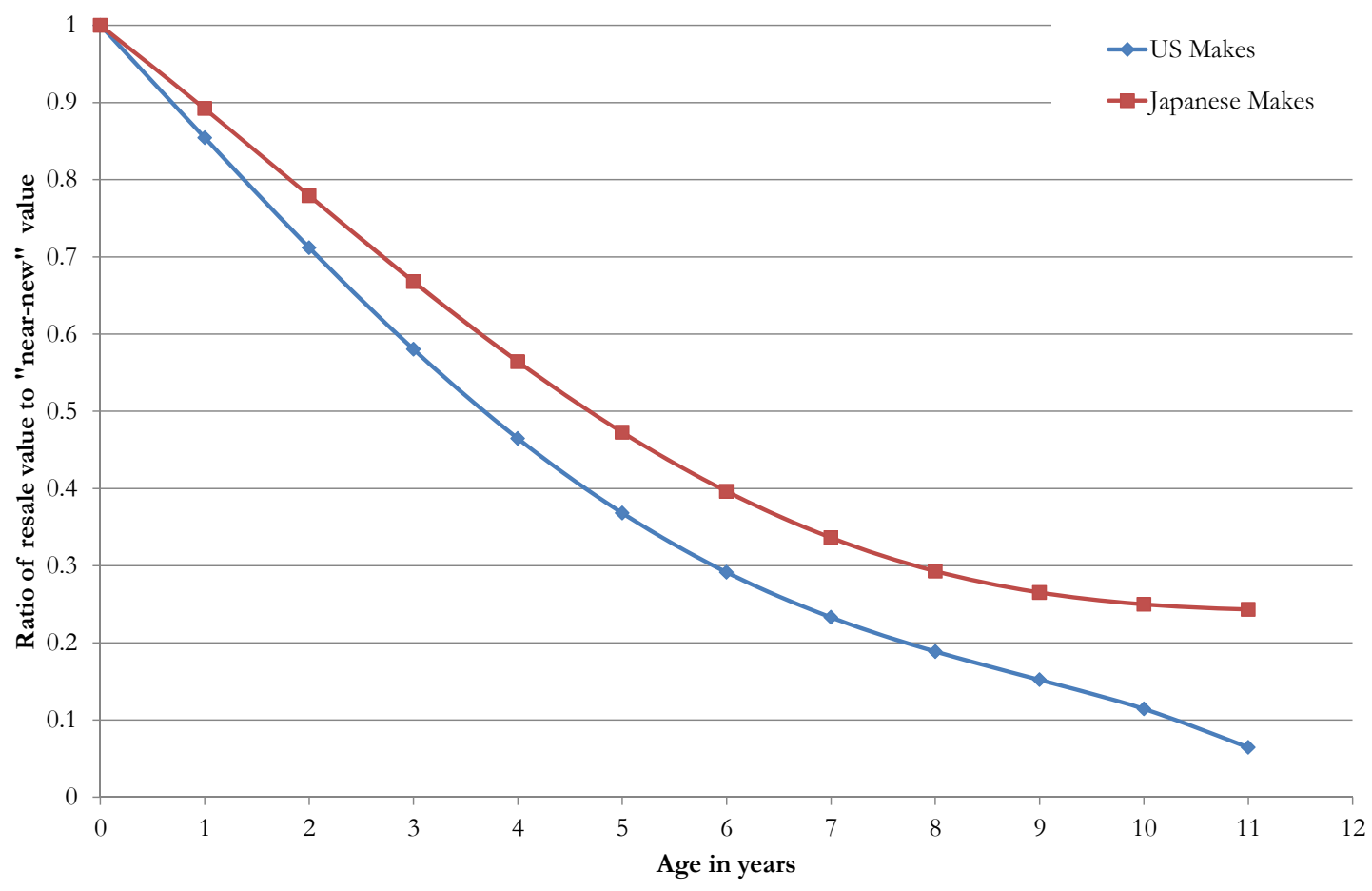


Figure 2: Average price by age, all cars in sample, by country of assembly

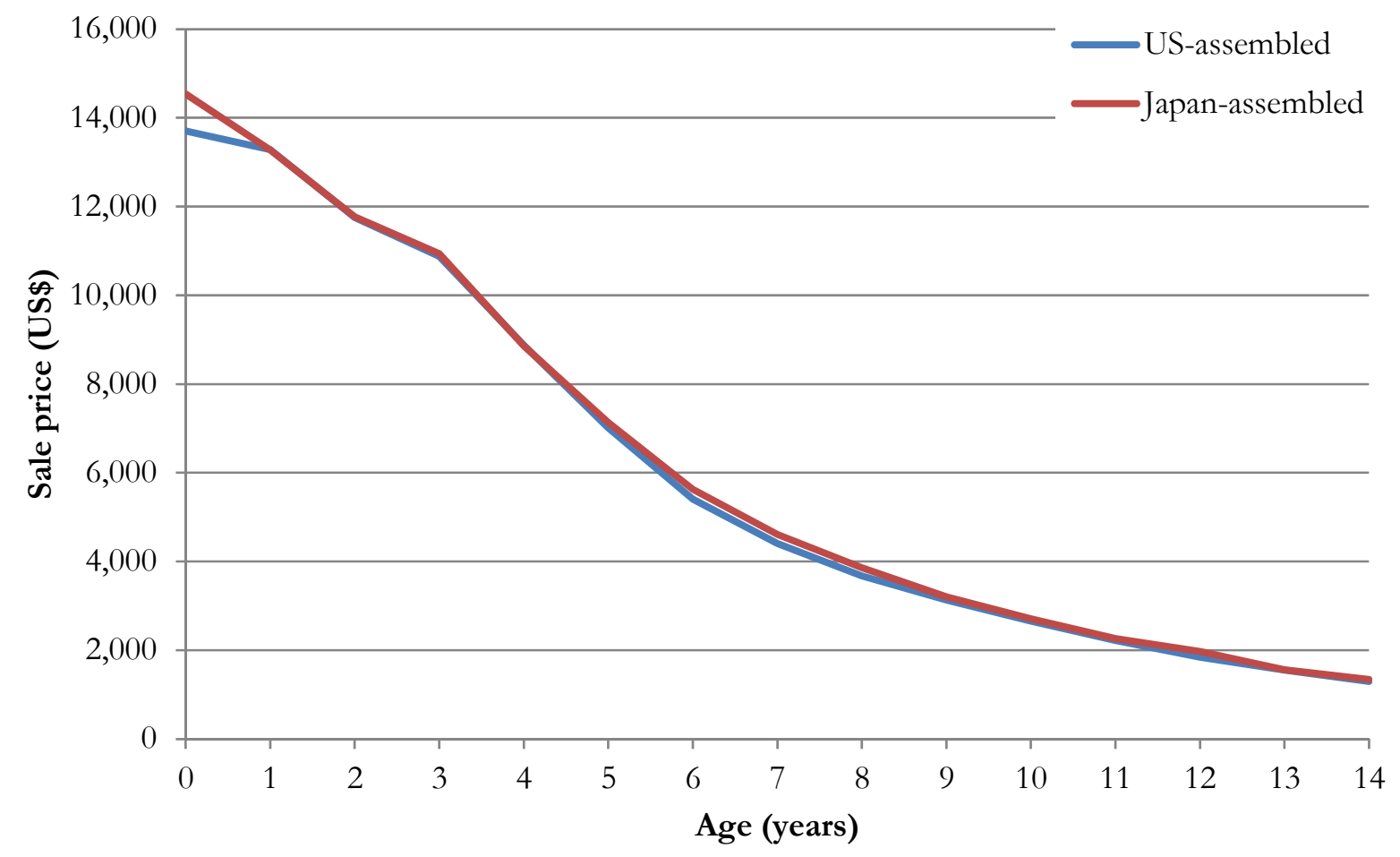


Figure 3: Average price by age for specific models

\section{A. Toyota Camry 4C 4D Sedan LE}

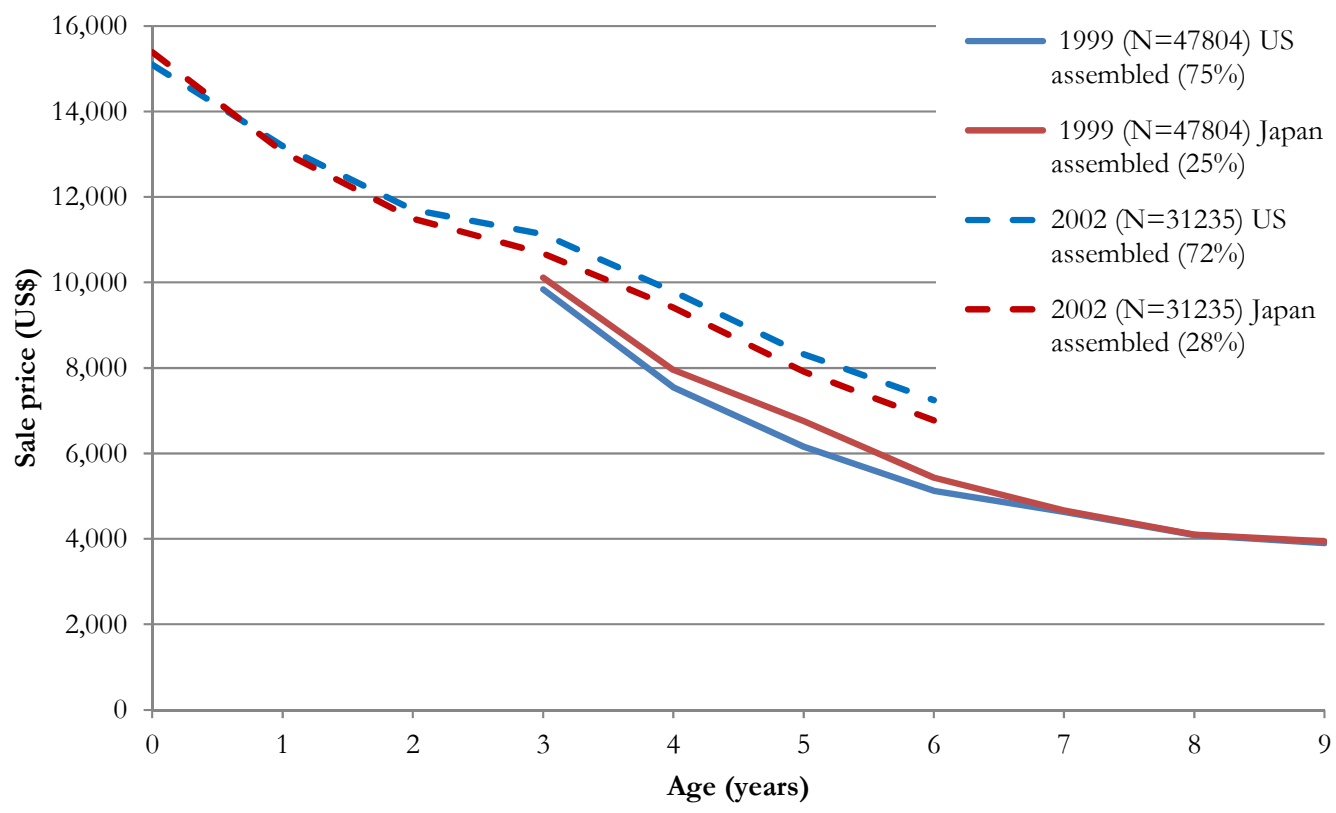

\section{B. Honda Accord 4C 4D Sedan LX Auto}

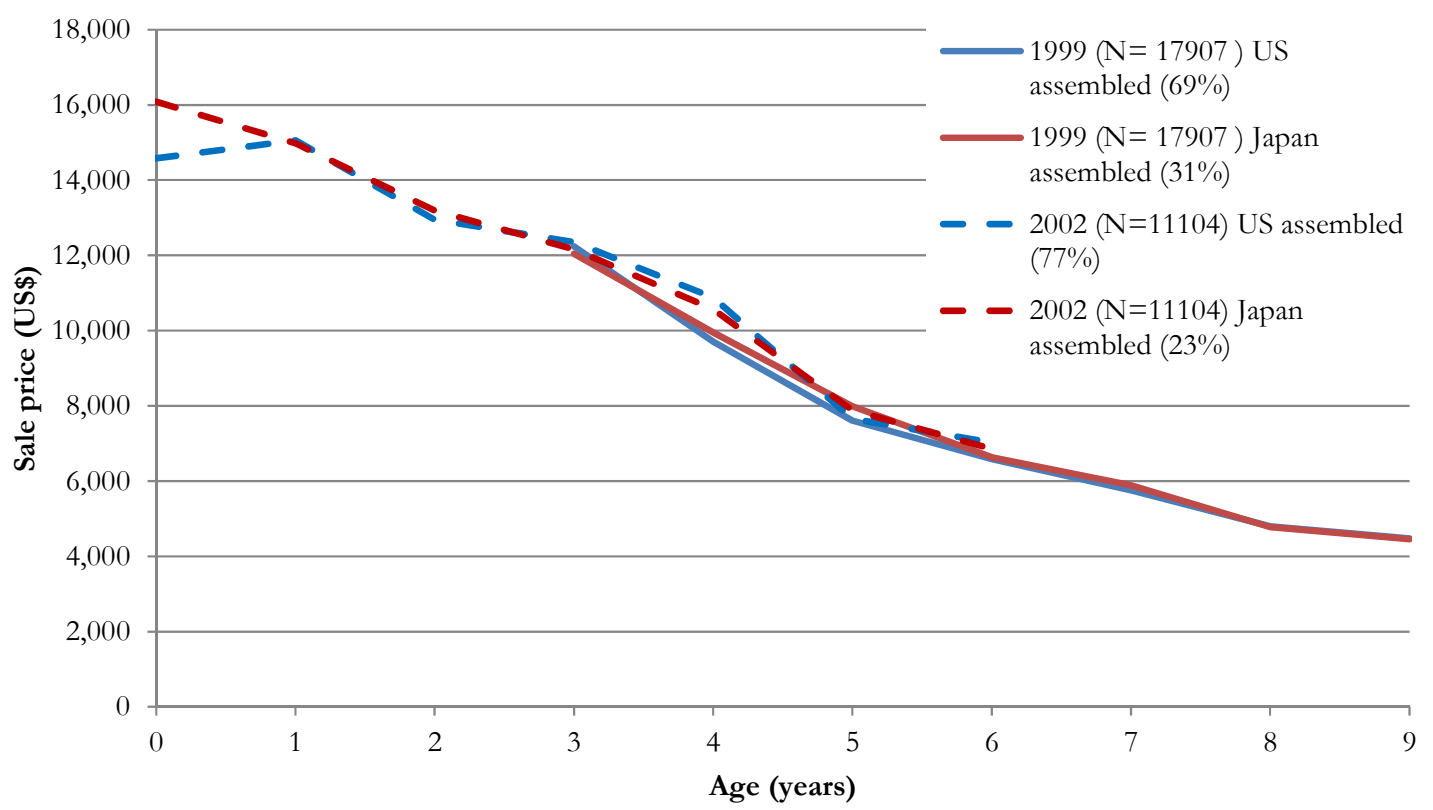


Figure 4: Comparison of fraction of cars assembled in Japan in auction data vs. production data

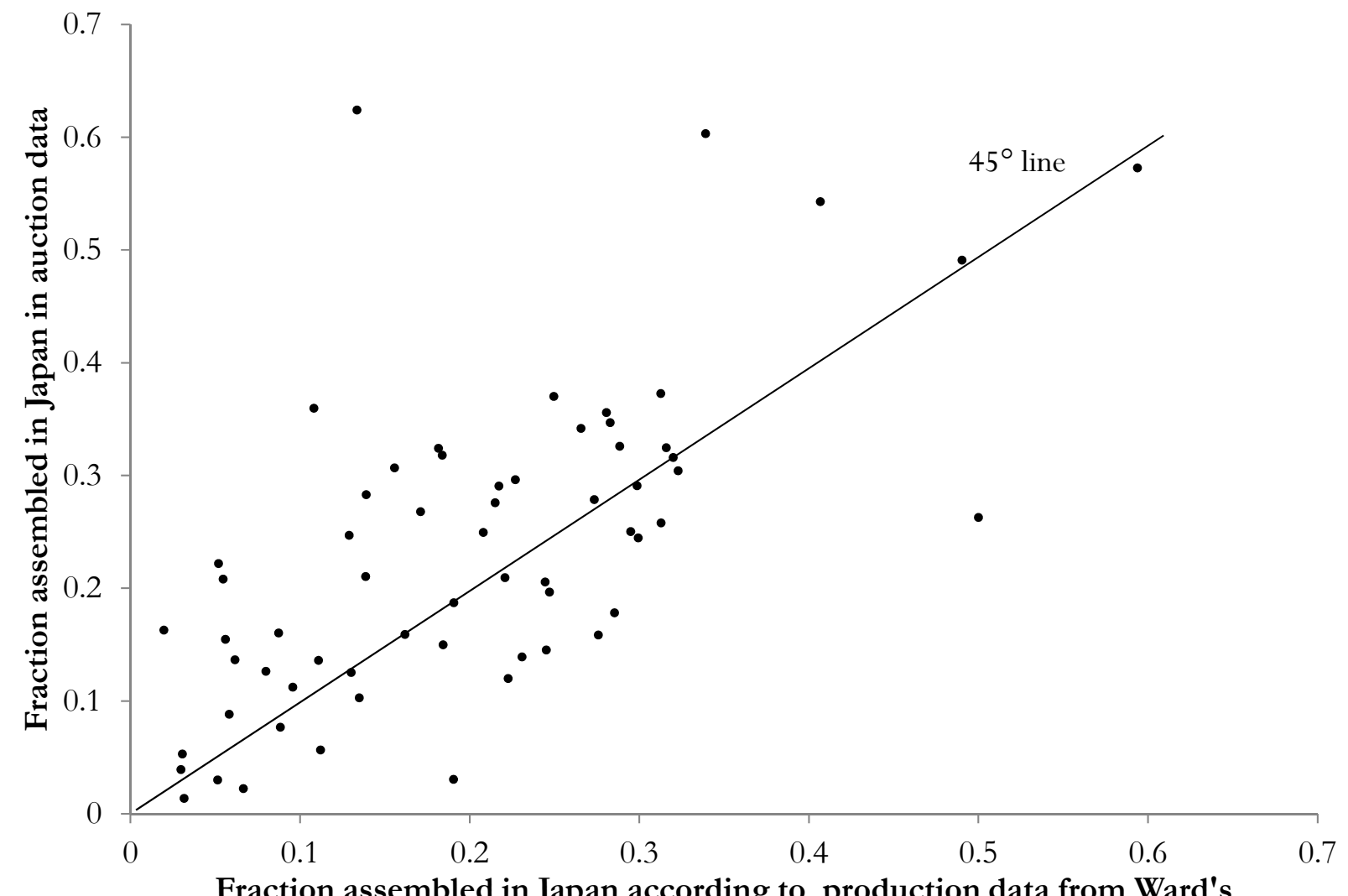

Fraction assembled in Japan according to production data from Ward's Automotive Yearbook 


\section{Figure 5: Quantile price difference analysis}

The black solid line reports the estimates of Japan-U.S. assembly price differences at different quantiles of the price distribution. The estimates are obtained as follows. First, we estimate quantile regressions of price on an indicator for the car being assembled in Japan and a mileage polynomial, separately for each car type (defined by the combination of make, model, body style, model year, auction year, and auction location). For each of the $10^{\text {th }}, 25^{\text {th }}, 50^{\text {th }}, 75^{\text {th }}$ and $90^{\text {th }}$ quantiles, an average of the estimates is obtained by weighting the estimates for each car type by the number of observations for that car type. The full set of observations is then re-sampled 200 and the procedure is repeated in order to derive the standard errors, from which the confidence intervals (black dotted lines) are obtained. The grey solid line reports the OLS estimate, and the grey dotted lines are the confidence intervals obtained through the same bootstrapping procedure described above.

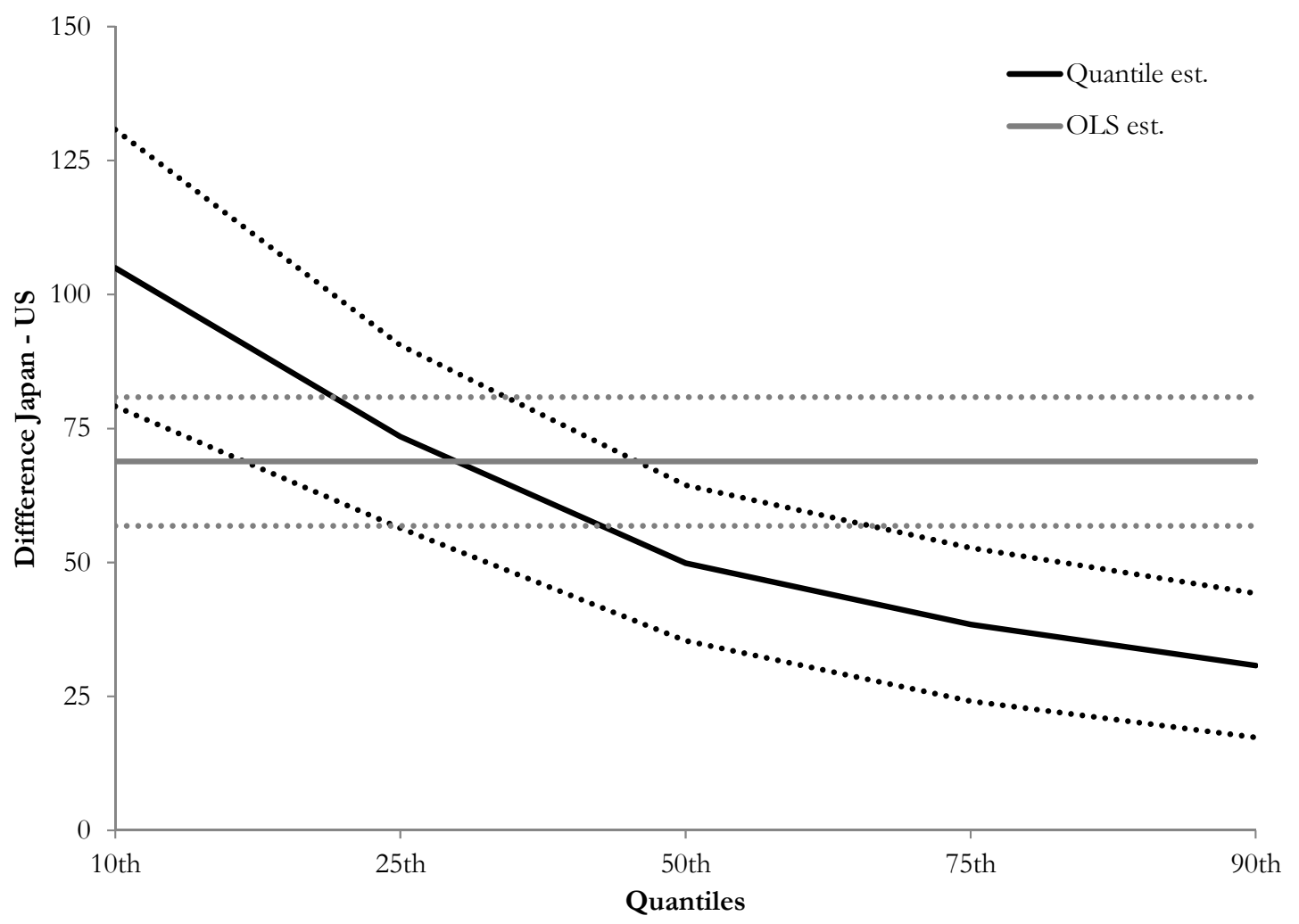


Figure 6: Price differences by country of assembly and model year for Toyota Camry and Honda Accord

The solid line in the two graphs below reports the estimates of the parameters $\beta_{t}$ from the following regression model: $\ln (P R I C E)_{i j}=\alpha+\sum_{t=1990}^{2008} I_{t} \beta_{t} J A P_{i}+f\left(X_{i}\right)+\delta_{j}+\varepsilon_{i}$, where $\ln ($ PRICE) is the natural log of price for a car $i$ of type $j$, and $\left(X_{i}\right)=\left(1+a g e_{i j}\right) \sum_{k=1}^{3}$ miles $^{k}$. The fixed effect $\delta j$ is the combination of make, model, model year, auction year, auction location, and seller type. The dotted lines represent the confidence intervals.

\section{A. Toyota Camry}

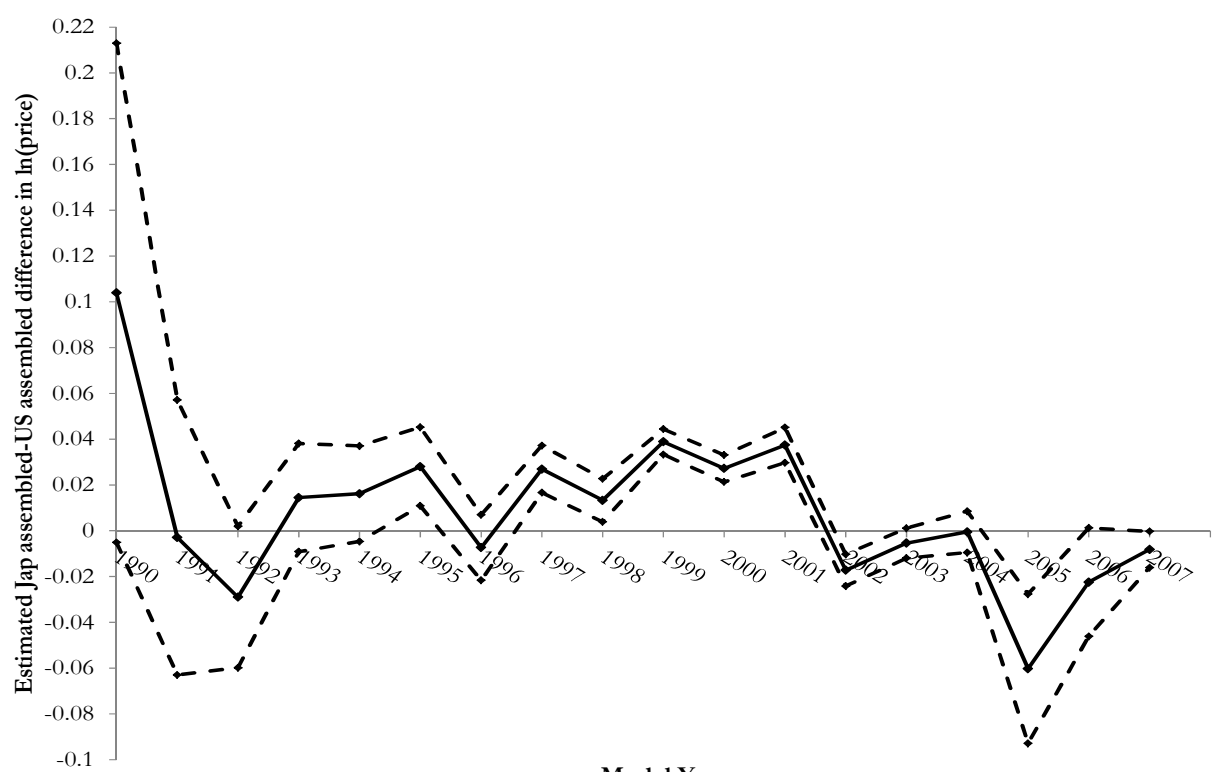

Model Year

\section{B. Honda Accord}

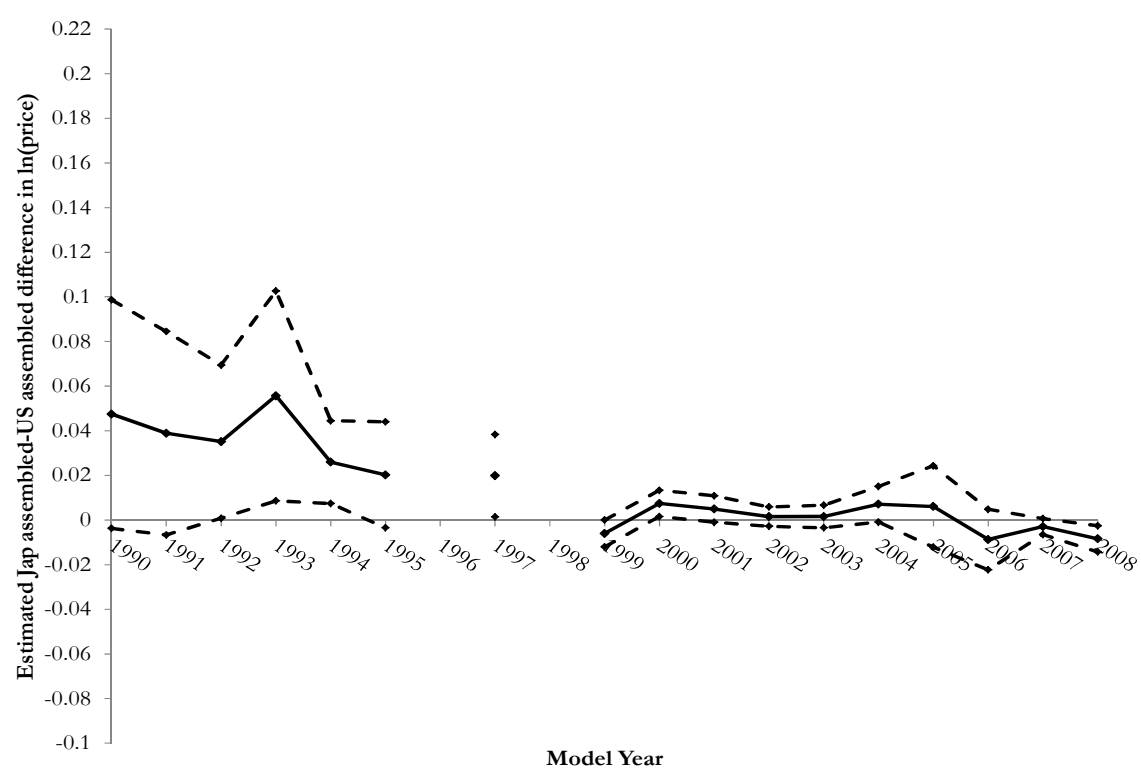




\section{Figure 7: Estimated Japanese vs. U.S. resale differences by model year and age}

The lines in these graphs show the estimated differences in sale prices for Japanese-built cars relative to U.S. assembled cars. Each line comes from a regression of cars from that model year (model year labeled for each line) and plots the coefficient estimates on an interaction between the Japan dummy and the car's age when auctioned. Each regression controls for a fixed effect that is the combination of the make, model, body style, model year, and auction location as well as a fourth-order polynomial in mileage.

\section{A. Toyota Camry 4C}

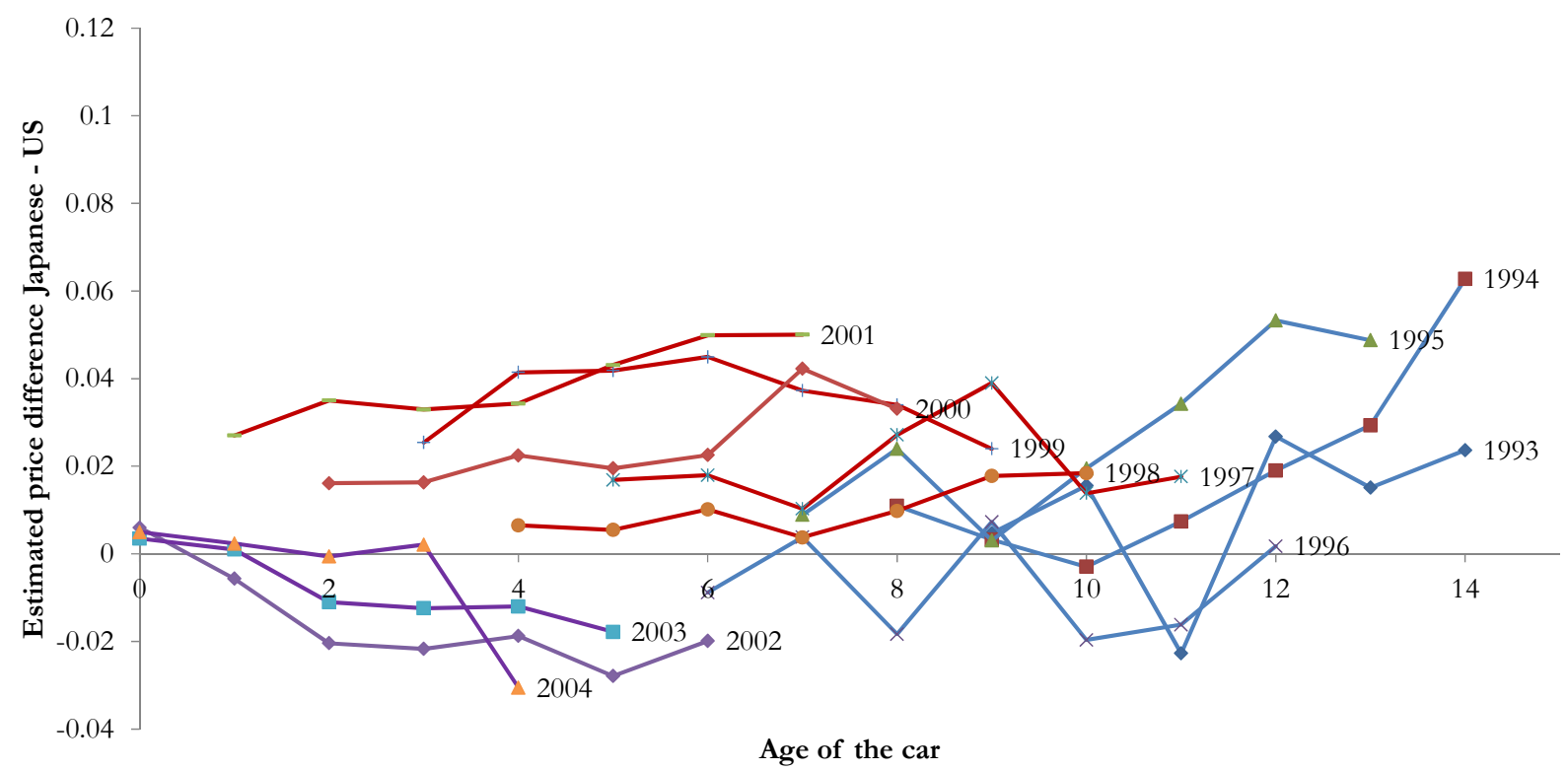

\section{B. Honda Accord 4C}

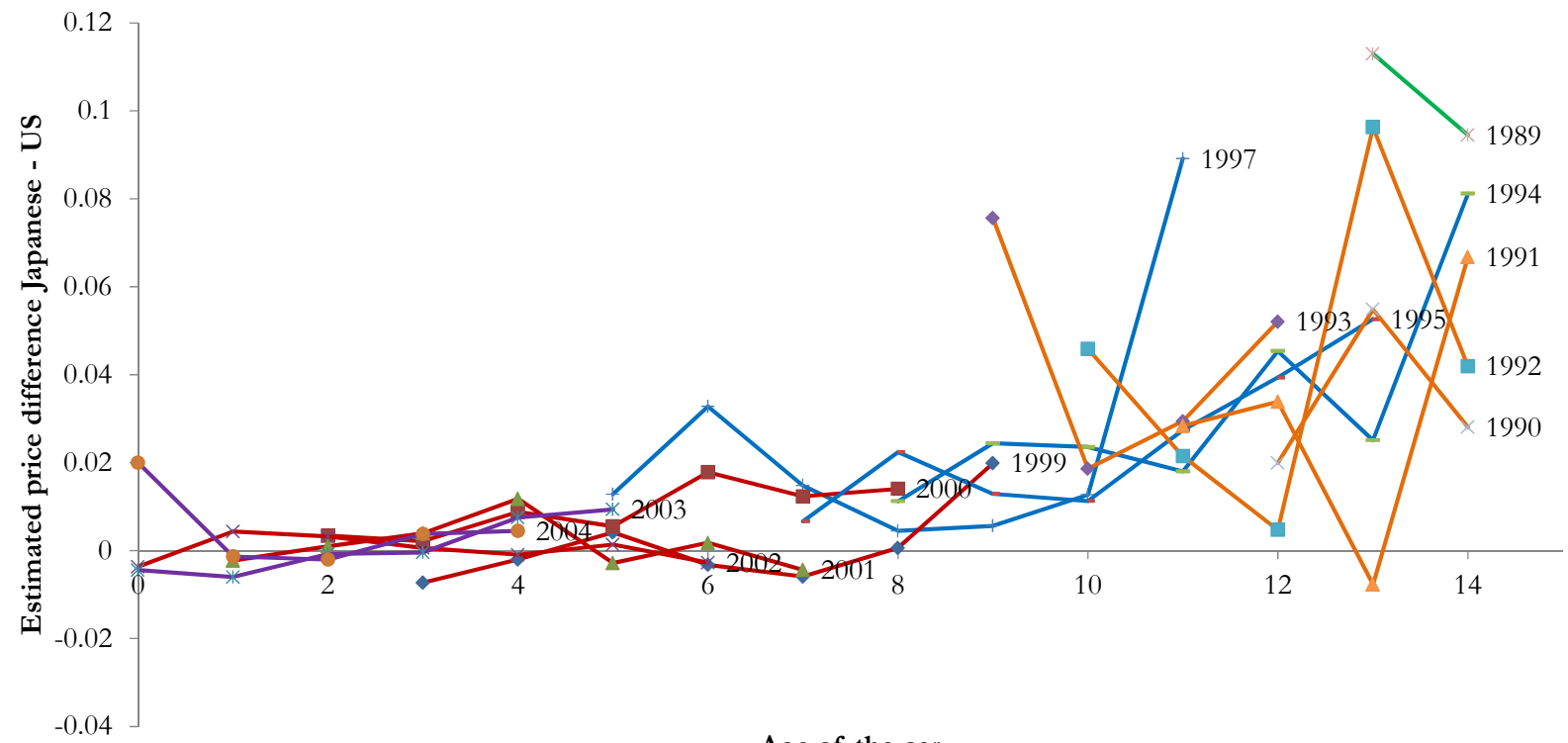

Age of the car 
Table 1: Summary Statistics

\begin{tabular}{lcccc}
\hline \hline & \multicolumn{2}{c}{ Full sample } & US-assembled & Japan Assembled \\
\hline & obs & mean & mean & mean \\
\cline { 2 - 5 } Model year & 565,652 & $1,999.64$ & $1,999.81$ & $1,999.16$ \\
Miles (in '000) & & $(3.79)$ & 3.80 & $(3.71)$ \\
& 565,652 & 72.67 & 71.62 & 75.67 \\
Age (years) & & $(48.1)$ & $(47.61)$ & $(49.35)$ \\
& 565,652 & 4.76 & 4.69 & 4.95 \\
Fraction of Honda & & $(3.33)$ & $(3.31)$ & $(3.38)$ \\
Fraction of Toyota & 565,652 & 0.37 & 0.36 & 0.39 \\
Fraction sold by dealers & 565,652 & 0.62 & 0.63 & 0.60 \\
Fraction in Western states & 565,652 & 0.64 & 0.65 & 0.62 \\
Fraction assembled in Japan & 556,806 & 0.23 & 0.16 & 0.41 \\
Price (\$) & 565,652 & 0.26 & & \\
& 360,774 & $8,545.89$ & $8,579.16$ & $8,455.01$ \\
Fraction reconditioned & & $(4169.07)$ & $(4192.88)$ & $(4101.95)$ \\
Estimated reconditioning expenses $(\$)$ & 565,606 & 193.67 & 195.78 & 0.27 \\
& & $(482.82)$ & $(485.61)$ & $(474.68)$ \\
Fraction classified in good condition & 565,652 & 0.07 & 0.07 & 0.05 \\
Fraction classified in bad condition & 565,652 & 0.02 & 0.02 & 0.02 \\
Fraction reported with green light & 251,138 & 0.75 & 0.76 & 0.73 \\
Fraction sold & 565,652 & 0.64 & 0.63 & 0.66 \\
Fraction arbitrated & 565,652 & 0.02 & 0.02 & 0.03 \\
\hline \hline
\end{tabular}

Note: Standard deviations in parentheses. 


\section{Table 2: Regression Results for Sale Price by Japan vs. U.S. Assembly}

This table reports the estimates of price differences from the following linear model: $P R I C E_{i j}=\alpha+\beta J A P A N_{i j}+$ $f\left(X_{i J}\right)+\delta_{j}+\varepsilon_{i J}$, where PRICE is in either level or natural log, and $\left(X_{i}\right)=\left(1+a g e_{i j}\right) \sum_{k=1}^{3} m_{i l e s}^{k}$. The composition of the fixed effect $\delta j$ is described in the table. Robust standard errors adjusted for clustering at the fixedeffect level (make, model, body style, model year, year at auction, auction location, seller type) are in parentheses. Significance: $* * * p<.01, * * p<.05, * p<.1$.

\begin{tabular}{|c|c|c|c|c|}
\hline \multirow[t]{2}{*}{ Sample } & \multicolumn{4}{|c|}{ Full sample } \\
\hline & (1) & (2) & (3) & (4) \\
\hline Dep. Var. & Price & Price & Price & $\ln$ (Price) \\
\hline Mean of Price & $8,545.89$ & $8,545.89$ & $8,545.89$ & $8,545.89$ \\
\hline JAPAN & $\begin{array}{c}125.1 * * * \\
(8.904)\end{array}$ & $\begin{array}{c}63.96 * * * \\
(7.473)\end{array}$ & $\begin{array}{c}61.66^{* * *} \\
(7.504)\end{array}$ & $\begin{array}{l}0.0114 * * * \\
(0.00105)\end{array}$ \\
\hline Fixed effects include: & & & & \\
\hline $\begin{array}{l}\text { Make, model, model } \\
\text { year, body style, } \\
\text { auction year }\end{array}$ & $\mathrm{X}$ & $\mathrm{X}$ & $\mathrm{X}$ & $\mathrm{X}$ \\
\hline $\begin{array}{l}\text { Fixed effects also } \\
\text { include }\end{array}$ & & $\begin{array}{l}\text { Auction } \\
\text { location }\end{array}$ & $\begin{array}{l}\text { Auction } \\
\text { location, } \\
\text { seller type }\end{array}$ & $\begin{array}{l}\text { Auction } \\
\text { location, } \\
\text { seller type }\end{array}$ \\
\hline Observations & 360,774 & 360,774 & 360,774 & 360,774 \\
\hline Adjusted R-squared & 0.939 & 0.946 & 0.947 & 0.933 \\
\hline Number of clusters & 9730 & 9730 & 9730 & 9730 \\
\hline
\end{tabular}




\section{Table 3: Regression Results for Alternative Quality Measures}

This table reports the estimates of price differences from the following model: $Y_{i j}=\alpha+\beta J A P A N_{i j}+f\left(X_{J i}\right)+\delta_{j}+$ $\varepsilon_{i J}$. In columns (1) and (3)-(5), the dependent variables are 0-1 indicators. In columns (1)-(4), both cars that sold and went unsold at the auctions are included. In column (1), the dependent variable is 1 if the car received a good condition report and 0 if the car either received a poor report or was not given a report. For column (3), cars that ran under a green light were advertised with no major defects, which contrasts with yellow lights (some stated defects) and red lights (sold "as is"). Data on the lights are available from 2005 and thereafter only, which is why the number of observations is lower. Once sold, cars may enter arbitration if the buyer feels the car was misrepresented by the seller during the auction. Only sold cars can be arbitrated, which is why there are fewer observations in column (5). Robust standard errors adjusted for clustering at the fixed-effect level are in parentheses. Significance: $* * * p<.01, * * p<.05, * p<.1$.

\begin{tabular}{|c|c|c|c|c|c|}
\hline \multirow[b]{2}{*}{ Dep Var. } & (1) & (2) & (3) & (4) & (5) \\
\hline & $\begin{array}{l}\text { Good } \\
\text { condition } \\
\text { report }\end{array}$ & $\begin{array}{c}\text { Estimated } \\
\text { conditioning } \\
\text { expenses }\end{array}$ & Green light & Sold & $\begin{array}{c}\text { Not } \\
\text { arbitrated }\end{array}$ \\
\hline Mean of Dep. Var. & 0.07 & 193.67 & 0.75 & 0.64 & 0.98 \\
\hline JAPAN & $\begin{array}{c}0.0003 \\
(0.0006)\end{array}$ & $\begin{array}{l}-3.033 \\
(1.943)\end{array}$ & $\begin{array}{c}0.0008 \\
(0.0024)\end{array}$ & $\begin{array}{c}0.0097 * * * \\
(0.0021)\end{array}$ & $\begin{array}{c}0.001 \\
(0.0008)\end{array}$ \\
\hline $\begin{array}{l}\text { Fixed effects include: } \\
\text { Make, model, model } \\
\text { year, body style, } \\
\text { auction year }\end{array}$ & $\mathrm{X}$ & $\mathrm{X}$ & $\mathrm{X}$ & $\mathrm{X}$ & $\mathrm{X}$ \\
\hline $\begin{array}{l}\text { Fixed effects also } \\
\text { include }\end{array}$ & $\begin{array}{l}\text { Auction } \\
\text { location, } \\
\text { seller type }\end{array}$ & $\begin{array}{l}\text { Auction } \\
\text { location, } \\
\text { seller type }\end{array}$ & $\begin{array}{l}\text { Auction } \\
\text { location, } \\
\text { seller type }\end{array}$ & $\begin{array}{l}\text { Auction } \\
\text { location, } \\
\text { seller type }\end{array}$ & $\begin{array}{l}\text { Auction } \\
\text { location, } \\
\text { seller type }\end{array}$ \\
\hline Observations & 565,652 & 565,606 & 251,138 & 565,652 & 360,774 \\
\hline Adjusted R-squared & 0.708 & 0.453 & 0.313 & 0.153 & 0.055 \\
\hline Number of clusters & 9732 & 9732 & 4826 & 9732 & 9730 \\
\hline
\end{tabular}




\section{Table 4: Additional robustness tests}

This table presents specifications, as in Table 2, on subsamples of the data and with the addition of further controls. In columns (1) to (4), the sample is split according to the type of seller: Fleet/lease and Dealers. In Columns (5)-(6), the sample excludes the car models for which the fraction of imports from Japan is different (in absolute value) by more than 15\% than from the fraction of imports of new Japanese cars as reported in the Ward's Automotive Yearbook (see Section 3.3 for details). In column (7), the quality measures used as outcome variables in Table 3 have been added as regressors. The omitted category for the dummies on the condition report is cars with no condition report. Cars that run under a yellow light have some stated defects and can only be challenged in arbitration for unannounced defects. Cars running under red lights are sold "as is." The omitted category for the light variables is given by cars that run under green lights, announcing no major defects. Data on lights are available only from 2005; hence, the smaller sample size. In Column (8), dummies for some specific options are added as controls. The sample size is smaller here as well because information on the options is available only from 2006. Robust standard errors adjusted for clustering at the fixed-effect level are in parentheses. Significance: $* * * p<.01, * * p<.05, * p<.1$.

\begin{tabular}{|c|c|c|c|c|c|c|c|c|c|}
\hline & \multirow[t]{2}{*}{ Sample } & \multicolumn{2}{|c|}{ Fleet/lease sellers } & \multicolumn{2}{|c|}{ Dealer sellers } & \multicolumn{2}{|c|}{ Excluding "wards' outliers" } & \multicolumn{2}{|c|}{ Full sample } \\
\hline & & (1) & (2) & (3) & (4) & (5) & (6) & (7) & (8) \\
\hline & Dep Var. & Price & $\ln$ (Price) & Price & $\ln$ (Price) & Price & $\ln$ (Price) & $\ln$ (Price) & $\ln$ (Price) \\
\hline & Mean of Price & 10802.32 & 10802.32 & 6666.1 & 6666.1 & 8496.17 & 8496.17 & 8678.29 & 8621.91 \\
\hline JAPAN & & $\begin{array}{c}84.55^{* * *} \\
(14.37)\end{array}$ & $\begin{array}{c}0.0109 * * * \\
(0.00150)\end{array}$ & $\begin{array}{c}42.66^{* * *} \\
(6.080)\end{array}$ & $\begin{array}{c}0.0117^{* * *} \\
(0.00144)\end{array}$ & $\begin{array}{c}63.24 * * * \\
(7.795)\end{array}$ & $\begin{array}{c}0.0117^{* * *} \\
(0.00109)\end{array}$ & $\begin{array}{c}0.00834 * * * \\
(0.00140)\end{array}$ & $\begin{array}{c}0.00873^{* * *} \\
(0.00174)\end{array}$ \\
\hline
\end{tabular}

Controls for quality measures

included

Controls for options measures

included

Fixed effects include: Make,

model, model year, body style, auction year

X $\quad$ X

X

$\mathrm{X}$

X

X

X

Auction location, Auction location, Auction location, Auction location, Auction location, Auction location, Auction location, Auction location,

Fixed effects also include seller type seller type $\quad$ seller type seller type $\quad$ seller type seller type $\quad$ seller type seller type

Observations

Adjusted R-squared

\begin{tabular}{cccccccc}
\hline 163,961 & 163,961 & 196,813 & 196,813 & 342,938 & 342,938 & 160,985 & 110,588 \\
0.854 & 0.835 & 0.961 & 0.925 & 0.947 & 0.933 & 0.941 & 0.936 \\
2316 & 2316 & 7414 & 7414 & 9134 & 9134 & 4825 & 3488 \\
\hline
\end{tabular}




\section{Table 5: Exploring heterogeneity across makes and over time: Price regressions}

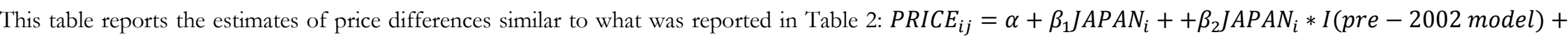
$f\left(X_{i}\right)+\delta_{j}+\varepsilon_{i}$, where PRICE is in either level or natural log, and $\left(X_{i}\right)=\left(1+a g e_{i j}\right) \sum_{k=1}^{3}$ miles ${ }^{k}$. The sample is split between the two major car makers in our sample (Toyota and Honda), and in addition to the JAPAN indicator, we add the interaction JAPAN *I(pre - 2002 model) to assess any changes in the JapanU.S. difference in older and more recent models. Therefore, the estimate $\widehat{\beta_{1}}$ gives the difference for models from 2002 onward, and $\widehat{\beta_{1}}+\widehat{\beta_{2}}$ is the estimated difference for models before 2002. The composition of the fixed effect $\delta$ j is described in the table. Robust standard errors adjusted for clustering at the fixed-effect level (make, model, body style, model year, year at auction, auction location, seller type) are in parentheses. Significance: $* * * p<.01, * * p<.05, * p<.1$.

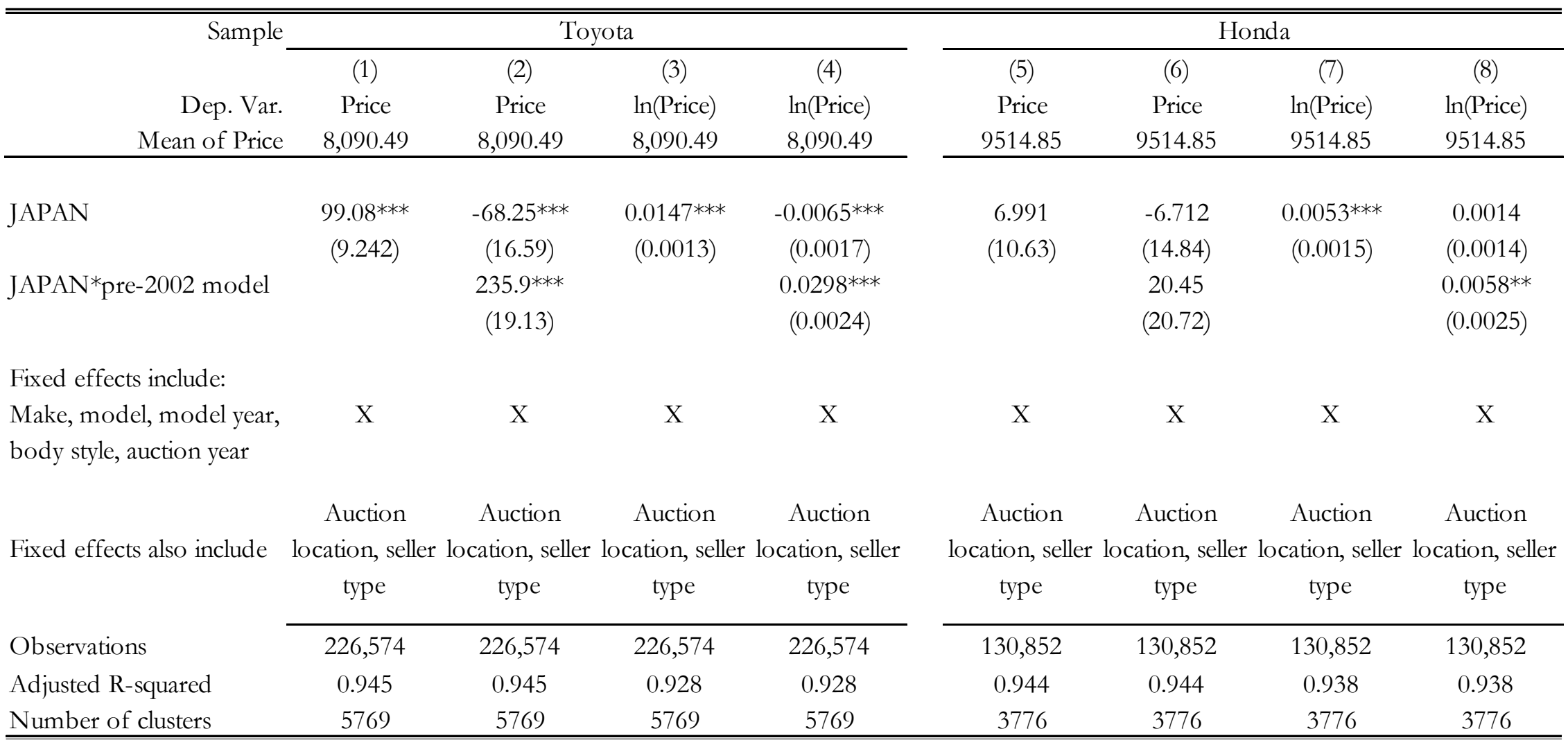




\section{Table 6: Exploring heterogeneity across makes and over time: Alternative quality measures}

This table reports the estimates of quality differences similar to what was reported in Table 3, with the addition of an interaction term between the Japan indicator and an indicator of pre-2002 models, as well as separately for Honda and Toyota vehicles. Robust standard errors adjusted for clustering at the fixed-effect level (make, model, body style, model year, year at auction, auction location, seller type) are in parentheses. Significance: $* * * p<.01, * * p<.05, * p<.1$.



